Article (refereed) - postprint

Schaller, Nathalie; Kay, Alison L.; Lamb, Rob; Massey, Neil R.; van Oldenborgh, Geert Jan; Otto, Friederike E.L.; Sparrow, Sarah N.; Vautard, Robert; Yiou, Pascal; Ashpole, lan; Bowery, Andy; Crooks, Susan M.; Haustein, Karsten; Huntingford, Chris; Ingram, William J.; Jones, Richard G.; Legg, Tim; Miller, Jonathan; Skeggs, Jessica; Wallom, David; Weisheimer, Antje; Wilson, Simon; Stott, Peter A.; Allen, Myles R. 2016. Human influence on climate in the 2014 southern England winter floods and their impacts. Nature Climate Change, 6 (6). 627-634. 10.1038/nclimate2927

Copyright (C) 2016 Macmillan Publishers Limited

This version available http://nora.nerc.ac.uk/509886/

NERC has developed NORA to enable users to access research outputs wholly or partially funded by NERC. Copyright and other rights for material on this site are retained by the rights owners. Users should read the terms and conditions of use of this material at http://nora.nerc.ac.uk/policies.html\#access

This document is the author's final manuscript version of the journal article, incorporating any revisions agreed during the peer review process. There may be differences between this and the publisher's version. You are advised to consult the publisher's version if you wish to cite from this article.

www.nature.com/ 


\section{Human influence on climate in the 2014 Southern 2 England winter floods and their impacts}

3 Nathalie Schaller ${ }^{1,2}$, Alison L. Kay ${ }^{3}$, Rob Lamb ${ }^{4,10}$, Neil R. Massey ${ }^{2}$, Geert Jan van 4 Oldenborgh $^{5}$, Friederike E. L. Otto ${ }^{2}$, Sarah N. Sparrow ${ }^{2}$, Robert Vautard ${ }^{6}$, Pascal 5 Yiou $^{6}$, Ian Ashpole ${ }^{2}$, Andy Bowery ${ }^{7}$, Susan M. Crooks ${ }^{3}$, Karsten Haustein ${ }^{2}$, Chris 6 Huntingford $^{3}$, William J. Ingram ${ }^{1,8}$, Richard G. Jones ${ }^{2,8}$, Tim Legg $^{8}$, Jonathan Miller ${ }^{7}$, 7 Jessica Skeggs ${ }^{9}$, David Wallom ${ }^{7}$, Antje Weisheimer ${ }^{1,11,12}$, Simon Wilson ${ }^{8}$, Peter A. 8 Stott $^{8}$ \& Myles R. Allen ${ }^{2,1}$

9 1: Department of Physics, Atmospheric Oceanic and Planetary Physics, University of 10 Oxford, Oxford OX1 3PU, UK

11 2: Environmental Change Institute, University of Oxford, South Parks Road, Oxford 12 OX1 3QY, UK

13 3: Centre for Ecology and Hydrology, Benson Lane, Wallingford OX10 8BB, UK

14 4: JBA Trust, South Barn, Broughton Hall, Skipton BD23 3AE, UK

15 5: Koninklijk Nederlands Meteorologisch Instituut, 3730 AE De Bilt, The Netherlands

16 6: Laboratoire des Sciences du Climat et de I'Environnement \& IPSL, UMR CEA-

17 CNRS-UVSQ, 91191 Gif-sur-Yvette, France

18 7: Oxford e-Research Centre, 7 Keble Road, Oxford OX1 3QG, UK

19 8: Met Office Hadley Centre, FitzRoy Road, Exeter EX1 3PB, UK

20 9: JBA Risk Management Ltd., South Barn, Broughton Hall, Skipton BD23 3AE, UK

21 10: Lancaster Environment Centre, Lancaster University, Lancaster LA1 4YQ, UK

22 11: Department of Physics, National Centre for Atmospheric Science (NCAS),

23 University of Oxford, Oxford OX1 3PU, UK

24 12: European Centre for Medium-Range Weather Forecasts (ECMWF), Reading 25 RG2 9AX, UK 
26 A succession of storms reaching Southern England in the winter of

27 2013/2014 caused severe floods and $£ 451$ million insured losses. In a

28 large ensemble of climate model simulations, we find that, as well as

29 increasing the amount of moisture the atmosphere can hold,

30 anthropogenic warming caused a small but significant increase in the

31 number of January days with westerly flow, both of which increased

32 extreme precipitation. Hydrological modelling indicates this increased

33 extreme 30-day-average Thames river flows, and slightly increased daily

34 peak flows, consistent with the understanding of the catchment's

35 sensitivity to longer-duration precipitation and changes in the role of

36 snowmelt. Consequently, flood risk mapping shows a small increase in

37 properties in the Thames catchment potentially at risk of riverine

38 flooding, with a substantial range of uncertainty, demonstrating the

39 importance of explicit modelling of impacts and relatively subtle

40 changes in weather-related risks when quantifying present-day effects

41 of human influence on climate. 
42 The winter of $2013 / 2014$, and January in particular, saw above-average precipitation over England and Wales ${ }^{1,2}$ and below-average sea level pressure (SLP) in the North Atlantic north and west of the British Isles (Fig. 1a-b). This persistent synoptic situation was associated with a nearcontinuous succession of low-pressure systems moving in from the Atlantic and across Southern England ${ }^{1}$. Like the very wet autumn of 2000 in England and Wales ${ }^{3}$, this winter was characterized by an anomalous eastward extension of the jet stream (Fig. 2a). This persistent atmospheric circulation pattern resulted in extreme precipitation (Supplementary Fig. 1), flooding and storm surges in large parts of Southern England and Wales, with serious consequences for infrastructure and livelihoods ${ }^{1}$. 18,700 flood insurance claims were reported ${ }^{4}$, leading to $£ 451$ million insured losses in Southern England. Although not unprecedented, this was a significant event; comparative UK insurance losses ${ }^{5}$ in recent history include flooding in the summer of 2007, which cost £3 billion, the 2005 floods in Carlisle (£272 million) and Cumbrian floods in November 2009 ( $£ 174$ million). Daily total precipitation, recorded since 1767 at the Radcliffe Observatory in Oxford (continuously since 1827), shows January 2014, as well as winter 2013/2014, precipitation set a record (Fig. $3 a$ ). Sustained high precipitation amounts during the whole winter led to this record, rather than a few very wet days, and none of the 5-day precipitation averages over the three winter months was a record (Fig. 3b). Similarly, while Thames' daily peak river flows were not exceptional, the 30-day peak flow was the second highest since measurements began in 1883 (Supplementary Fig. 10). Whether anthropogenic climate change contributed to this event was much discussed at the time, with the British Prime Minister David Cameron telling Parliament "I very much suspect that it is"6. Although in a chaotic system a single extreme event cannot be attributed to changes in boundary conditions ${ }^{7}$, the change in risk of a class of extremes in the current climate relative to a climate unaltered by anthropogenic greenhouse gas (GHG) emissions can be estimated ${ }^{8}$. This study uses a range of models and observations to estimate anthropogenic influence on the risk of experiencing such atmospheric flow and precipitation, 
74 separating thermodynamic and dynamic factors. To estimate the impacts of climate change, we use a hydrological model to calculate the anthropogenic changes in risk in peak flows of the river Thames. Finally, with detailed flood maps of the Thames basin, we estimate the number of properties put at additional risk of flooding by anthropogenic GHG emissions.

\section{Experimental setup and model evaluation}

We use the citizen-science project "weather@home" to produce an ensemble of 134,354 simulations of possible weather under current climate and under counterfactual conditions as might have been without human influence on atmospheric composition. This project uses spare CPU time on volunteers' personal computers to run the regional climate model (RCM) HadRM3P nested in the HadAM3P atmospheric general circulation climate model $(A G C M)^{9}$ driven with prescribed sea surface temperatures (SSTs) and sea ice concentration (SIC). The RCM covers Europe and the Eastern North Atlantic Ocean, at a spatial resolution of about $50 \mathrm{~km}$. 17,367 winters (December, January and February: DJF) were simulated under observed 2013/2014 GHG concentrations, SSTs and SIC ("Actual Conditions"). Initial conditions are perturbed slightly for each ensemble member on December 1 to give a different realisation of the winter weather ${ }^{9}$. The remaining simulations ("Natural") represent different estimates of conditions that might have occurred in a world without past emissions of GHGs and other pollutants including sulphate aerosol precursors. In the Natural simulations, atmospheric composition is set to pre-industrial, the maximum well-observed SIC is used (DJF 1986/1987, the precise choice is unimportant: Supplementary Fig. 5) and estimated anthropogenic SST change patterns are removed from observed DJF 2013/2014 SSTs. To account for the uncertainty in our estimates of a world without anthropogenic influence, 11 different patterns are calculated from GCM simulations of the Coupled Model Intercomparison Project phase 5 (CMIP5) $^{10}$ (Supplementary Information Section 2). We include all CMIP5 models with at least 3 ensemble members available regardless of 
how well their simulated trends fit observed SST trends in the North Atlantic, to provide a conservative estimate of uncertainty.

We consider January precipitation and SLP, with Southern England Precipitation (SEP) averaged over land grid points in $50^{\circ}-52^{\circ} \mathrm{N}, 6.5^{\circ} \mathrm{W}-2^{\circ} \mathrm{E}$. Simulated anomalies for Actual Conditions ensemble members with the wettest $1 \%$ SEP, i.e. return periods of 1-in-100-year and rarer, are comparable to observations of January 2014, consistent with previous model evaluation $^{9}$ (Fig. 1c-d). The mean climate of the RCM has a wet bias of $\sim 0.4$ $\mathrm{mm}$ day $^{-1}$ in January over Southern England ${ }^{9}$ but most RCM simulations for January 2014 show smaller anomalies than observed, and show a weaker SLP pattern for the same precipitation anomaly (Fig. 1c-d). On average, the Actual Conditions simulations reproduce a stronger jet stream, compared to the 1986-2011 climatology, of January 2014 in the North Atlantic (ERAInterim ${ }^{11}$, Fig. 2a-b), suggesting some potential predictability for the enhanced jet stream of January 2014. The differences in SSTs, SICs and atmospheric composition between Actual Conditions and Natural simulations lead to an increase of up to $0.5 \mathrm{~mm} \mathrm{day}^{-1}$ in the wettest $1 \%$ ensemble members for January SEP (Supplementary Fig. 8). While a warmer atmosphere holds more water vapour, causing an increase in risk of heavy winter rainfall, a dynamic effect, where anthropogenic forcings altered probability of occurrence of the atmospheric circulation that favoured the winter $2013 / 2014$ conditions $^{12}$, is also possible. Disentangling whether a change in precipitation extremes is caused by anthropogenic forcing via thermodynamic or dynamic processes remains a major challenge ${ }^{3,13}$, which we now address.

\section{Relationships between atmospheric circulation and precipitation}

To investigate the joint changes in precipitation and circulation, the observed and modelled Atlantic flows are classified into four main weather regimes using a classical cluster analysis ${ }^{14-16}$ (Supplementary Information Section 3). During January 2014, the atmospheric circulation was classified on 26 out of 31 days as "zonal regime" (ZO). This is the highest ZO occupancy in January 
136 since 1871 (Supplementary Fig. 7f). The winter as a whole also set a record

137 (70\% of days in ZO), in both cases with record low pressure northwest of 138 Scotland $\left(20^{\circ} \mathrm{W}, 60^{\circ} \mathrm{N}\right.$, the centre of the anomaly associated with the $\mathrm{ZO}$ 139 regime, Supplementary Fig. $7 b$, and where SLP is strongly associated with 140 SEP, Supplementary Fig. 2a). In the following we use these two circulation 141 indices - the January average SLP Northwest of Scotland and the number of 142 days spent in the ZO regime - to characterize the circulation and its changes. 143 In the RCM simulations, anthropogenic forcing is found to affect the joint 144 distribution of precipitation in Southern England with both low pressure and 145 ZO occupancy (Figs $4 a-b$ ). The joint distribution of the Actual Conditions 146 ensemble is stretched towards lower pressures (higher ZO occupancies) and 147 higher precipitation compared to the pooled Natural ensemble, while the other 148 end of the joint distribution (lower precipitation and higher pressure) is 149 unaffected. The model shows more low-pressure systems and days in the ZO 150 regime in the current climate than in the counterfactual world without human 151 influence on climate, with correspondingly higher monthly precipitation 152 amounts in Southern England. Fig. 5a shows the return period (i.e. the 153 inverse of the tail probability) of the pressure index values for all ensembles. 154 Comparing return periods in the Actual Conditions and Natural ensembles 155 gives the change in risk. The risk of experiencing a 1-in-100-year low156 pressure event Northwest of Scotland in the Actual Conditions ensemble 157 increases by a best estimate of $55 \%$ due to climate change (with an 158 uncertainty range of no change to over $120 \%$ increase). We have used all 159 ensemble members available from the individual Natural simulations as our 160 best estimate (Supplementary Information Section 2 discusses this choice 161 and sensitivity of our results to it).

162 This change in risk is of similar amplitude to the difference from the 19861632011 climatology (grey dots) and implies that the anomalous circulation in 164 January 2014 was both a response to the January 2014 SSTs and sea ice 165 concentration, hence potentially predictable, and influenced by anthropogenic 166 forcing. 
167 Even with these SSTs, however, it still appears to have been relatively 168 unlikely: monthly ZO occupancy of 24 days have on average a return period 169 of 1-in-151-year in the pre-industrial climate (uncertainty range: 1-in-104-year 170 to 1-in-230-year), which changes to 1-in-113-year due to climate change (Fig. $1715 \mathrm{~b})$. Flows under the $\mathrm{ZO}$ regime have an eastward-extended jet stream 172 towards European coasts. A higher frequency of $\mathrm{ZO}$ regimes is thus 173 consistent with recent studies of the effect of climate change on limiting large 174 latitudinal fluctuations of the jet-stream ${ }^{17}$, thereby favouring occupancy of 175 regimes like $\mathrm{ZO}$, in line with Ref 18 . Our results are not inconsistent with 176 studies reporting insignificant future mean changes of the North Annular Mode 177 or North Atlantic Oscillation (NAM/NAO) ${ }^{17,19}$ because we are detecting a weak 178 signal in extremes, in a much larger ensemble than previously used.

179 To examine changes in the frequency of extreme precipitation events, we use $180 \mathrm{RCM}$ outputs for the Southern England region and average observations from 1818 stations in this region with long records in Met Office archives. Using the 182 time series from 1912-2013 for these 8 stations alone (Supplementary Fig. 1) 183 and treating individual months as independent, the best estimate of the return 184 period of January 2014 SEP is around 85 years ( $90 \%$ confidence interval of 185 35-550 years; Fig. 5c). Observed Southern England monthly winter 186 precipitation amounts show no statistically significant change in extreme 187 values between the recent period and a century ago using a simple statistical 188 model, although the sensitivity of the test is low (Supplementary Information 189 Section 4).

190 In the large RCM ensemble, the best estimate for the overall change in risk of 191 a 1-in-100-year January precipitation event pooling all the Natural simulations 192 is an increase of $43 \%$, with a range from no change to $164 \%$ increase 193 associated with uncertainty in the pattern of anthropogenic warming (Fig. 5d). 194 Supplementary Fig. 5 shows that this uncertainty is mainly caused by the 195 difference in SSTs and is not affected by the exact choice of sea ice 196 conditions. The potential predictability identified for the pressure index (Fig. 197 5a) does not appear to extend to precipitation for which the climatological 
distribution is consistent with the Actual Conditions ensemble. The Natural ensemble with the smallest change in risk of 1-in-100-year precipitation between Actual and Natural conditions (with the SST pattern from the HadGEM2-ES model) also shows a similar jet stream anomaly to the Actual Conditions ensemble (Fig. 2c). There is no such anomaly in the Natural ensemble showing the greatest change in this risk (with the SST pattern from the CCSM4 model, Fig. 2d).

The 11 estimates of the SST response to anthropogenic forcing allow a statistical investigation into the drivers of the dynamic response. The obvious candidate indices are the global-mean warming and the anthropogenic change in meridional SST gradient upstream (since mid-latitude cyclones are forced by the atmospheric meridional temperature gradient). We represent the latter by the difference between the regions $30^{\circ} \mathrm{N}-50^{\circ} \mathrm{N}, 40^{\circ} \mathrm{W}-0^{\circ} \mathrm{W}$ and $50^{\circ} \mathrm{N}-70^{\circ} \mathrm{N}, 40^{\circ} \mathrm{W}-0^{\circ} \mathrm{W}$. Correlations across the 11 anthropogenic SST change patterns of the change in 1-in-100-year SEP with the global-mean warming and the anthropogenic change in meridional SST gradient upstream are 0.73 and 0.74 (in line with previous studies ${ }^{20,21}$ ) respectively (notional $p$ value of 0.01 using a $t$-test). As expected, these two indices are themselves correlated, but only at 0.44 ( $p$-value of 0.17 ). Dividing the change in gradient by the global-mean warming to leave only the pattern of change, not of its magnitude, still gives a correlation of 0.69 ( $p$-value of 0.02 ). Thus both largescale warming and local dynamical changes play a role.

We estimate the relative importance of thermodynamic and dynamic effects by using the pressure index as a proxy for the changes in circulation between Actual Conditions and Natural simulations. By weighting the Natural ensemble members to match the distribution of the Actual Conditions pressure index values (Fig. 4c and Supplementary Information Section 5) and applying this weighting to the precipitation index to remove the effect of circulation (Fig. $4 d$ ), we estimate that the increase in risk of the 1-in-100-year precipitation event due to anthropogenic forcing is caused approximately $2 / 3$ by 
228 thermodynamic changes, and approximately $1 / 3$ by circulation changes. Previous studies such as Ref 3 found only a thermodynamic influence.

3. Attributing changes in impacts

Modelled precipitation and temperature are fed into the CLASSIC hydrological model of the Thames catchment ${ }^{22}$, spun up with observed data from January 2010 to early December 2013 (Supplementary Information Section 6).

For a 1-in-100-year event in the hydrological model, anthropogenic climate change increased the modelled risk of 30-day peak river flows at Kingston by a best estimate value of $21 \%$ (uncertainty range: $-12 \%$ to $133 \%$ ) (Fig. $5 e$ ). For daily peak flows however, the increase was a best estimate of $4 \%$ (uncertainty range: $-17 \%$ to $30 \%)$. The impacts on daily peak flows are moderated by changes in snow (Supplementary Section 6.4). Snow has historically been one of the primary flood-generating mechanisms in the lower Thames (typically via rapid melt of large accumulations coincident with heavy rainfall, as occurred to cause the major flooding of March 1947), but has been less common in recent years ${ }^{23}$. However, the other primary flood-generating mechanism in the lower Thames is sustained heavy rainfall (typically over 4-7 days) on saturated ground ${ }^{23}$. Thus differences in the anthropogenic influence on extreme 5-day and 30-day rainfall accumulations (Supplementary Fig. 14) further explain the more modest impacts on daily peak flows compared to 30day peak flows. These differences between 30-day and 5-day rainfall accumulations are correlated with the SST gradients of the 11 Natural ensembles at 0.65 ( $p$-value of 0.03 ). Thus the anthropogenic increase in rainfall that we simulate is less on timescales that dominate flooding in this catchment, consistent with the mechanism being an increase in the frequency of the zonal regime, and so, successions of strong but fast-moving storms.

Outputs from CLASSIC are combined with information about the location of properties at risk of flooding in the Thames catchment, for flood events of various magnitudes, in order to estimate the change in numbers of properties 
at risk (Supplementary Information Section 7). These estimates are derived using methods previously applied for official government flood zone maps in England $^{24}$ (incorporating subsequent improvements in data and modelling). The Ordnance Survey, Britain's official mapping agency, supplied property location data. Changes in risk reported here are calculated using daily peak flows, the closest available approximation to the data used in modelling properties at risk, even though the effects of changes in forcing are greater for flow volumes integrated over longer durations.

For events with around a 100-year return period, the best estimate is that about 1,000 more properties are placed at risk of flooding in a human-altered climate (Fig. 5f). Again, the results span a range of possible outcomes from around 4,000 fewer to 8,000 more properties at risk. The average flood insurance claim during the period DJF 2013/2014 (which predominantly reflects flooding in Southern England, especially around the Thames) is reported by industry sources ${ }^{4}$ to be approximately $£ 24,000$. Therefore the best estimate additional exposure to flood risk in an event similar to DJF $2013 / 2014$ would be about $£ 24$ million in terms of potential losses (uncertainty range -£96 million to £192 million) suggesting a non-negligible contribution to risk when taking account of the ensemble uncertainty around the central estimate. Although there is only a small (ensemble average) increase in daily peak flows the results suggest that when winter flooding of the Thames does occur, it could be lasting longer which has implications both for damages and civil emergency management.

The only human influence considered here is the change in atmospheric composition. In both Actual and hypothetical Natural conditions, the flood risk would have been affected by anthropogenic interventions, in particular flood defences, although only a relatively small proportion of floodplain properties benefit from significant defences (Supplementary Information Section 7) and it is not known how that infrastructure might have evolved in the counterfactual world represented in the Natural ensembles. 
This is the first end-to-end attribution study from anthropogenic changes in atmospheric composition, through a meteorological extreme event and its hydrological impacts to an estimate of the value of those impacts in terms of flood damages. It illustrates how even relatively subtle changes in weatherrelated risks could potentially have significant monetary impacts. In summary we find that human influence:

- Increased the risk of low pressure Northwest of Britain and the number

All these cases have large uncertainties due to sensitivity to the uncertain geographical pattern of anthropogenic SST warming. We further estimate that while thermodynamic effects cause most of the increase in precipitation, around $1 / 3$ is caused by changes in circulation.

Our results illustrate the importance of considering changing risks of extreme weather in quantifying climate change impacts and highlights that a holistic assessment of the risk requires the consideration of both the thermodynamic and dynamic response of the climate system to human-induced changes in the atmospheric composition 25,26 .

Although the central estimate of increase in the number of properties at risk is small, the ensemble uncertainty spans a range of changes in flood damages that includes some chance of reductions, and also a substantial chance of increased damages that would be significant relative to total flood claims during DJF 2013/2014. A broader assessment could include the risks from storm surge in the Thames estuary and from a wider range of extreme 
317 weather and flood events. It should be noted that this analysis does not

318 account for other factors influencing flood risk in southern England, including

319 continuing development on flood plains and levels of spending on flood

320 defences that have been criticized as inadequate ${ }^{27}$, nor that some residual

321 risk will need to be managed under investment strategies regarded as

322 economically optimal ${ }^{28,29}$. It is noted that impacts on flows and damages for

323 other catchments are likely to differ from those estimated for the Thames at

324 Kingston, because of differences in catchment characteristics and potential

325 spatial differences in rainfall patterns.

326 This study is based on one AGCM where physical model uncertainty is 327 represented only by the differing SST patterns representing the difference 328 between current and pre-industrial obtained from 11 different GCMs. It would 329 clearly be desirable to replicate these results with a broader range of climate 330 models to better understand the sensitivities to model formulations as well as 331 biases and forcings, including model resolution and the pattern and 332 magnitude of the anthropogenic SST signal used to simulate the 'climate that 333 might have been' without human influence. Similarly, potential sensitivity of 334 results to the choice of hydrological model should be assessed, although this 335 is likely to be less important than the choice of climate mode ${ }^{30}$. More studies 336 of this nature are needed if loss and damage from anthropogenic climate 337 change are to be quantified objectively ${ }^{31}$ and future assessments of the 338 impacts of climate change are to progress from attributing them simply to 339 changes in climate which are not themselves explained ${ }^{32}$, to attributing them 340 specifically to human influence ${ }^{33}$. 
341 Correspondence should be addressed to Nathalie Schaller

342 (Nathalie.Schaller@physics.ox.ac.uk)

\section{Acknowledgements}

345 The authors thank the climateprediction.net participants whose generous

346 donation of their spare computer processing power has enabled the large 347 model ensembles to be created. Thanks to Tim Palmer for suggesting Fig. 2, 348 to Sarah Kew for assistance with the kernel density estimates, and to Maliko 349 Tanguy and Virginie Keller for producing the CEH-GEAR data for 2013/2014 350 ahead of schedule. We further thank JBA Risk Management Ltd. for 351 permission to use data derived from their GB Comprehensive Flood Map, 352 based on Astrium digital terrain data. Property locations were derived from 353 AddressPoint data, used with kind permission of Ordnance Survey. NS, NRM, 354 GJvO, RV, PY, AW, PAS and MRA were supported by the EUCLEIA project 355 funded by the European Union's Seventh Framework Programme [FP7/2007356 2013] under grant agreement no. 607085. NS received additional support 357 from the Swiss National Science Foundation. NRM, FELO, SNS, WJI, AB, JM 358 \& DW also received support from the NERC HYDRA Changing Water Cycle 359 project. ALK, SMC and $\mathrm{CH}$ were supported by the $\mathrm{CEH} / \mathrm{NERC}$ National 360 Capability fund. PAS, WJI and RGJ were also supported by the UK Joint 361 Department for Energy and Climate Change (DECC), Department for 362 Environment, Food and Rural Affairs (Defra) MOHC Climate Programme 363 (GA01101).

\section{Author contributions}

NS, AK, RL, GJvO, RV, PY, PAS and MRA designed the study, NS, AK, RL, NRM, AB, JM, JS set up and performed model experiments, NS, AK, RL, NRM, GJvO, FELO, SNS, RV, PY, KH, CH, TL and JS provided analyses and all authors wrote the paper. 
a

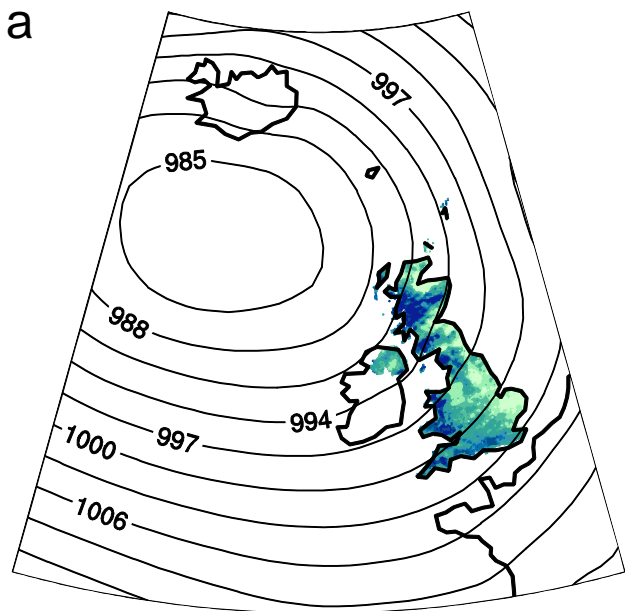

C
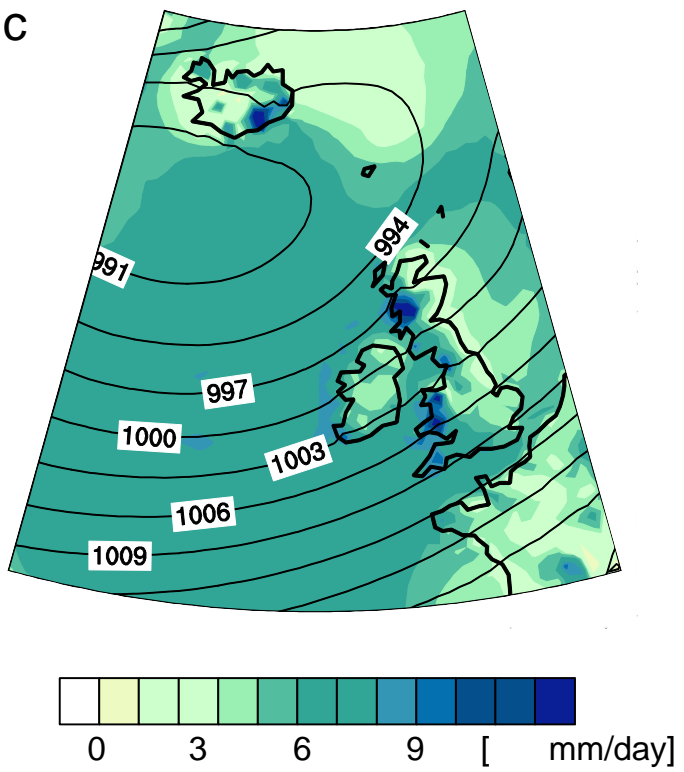

b

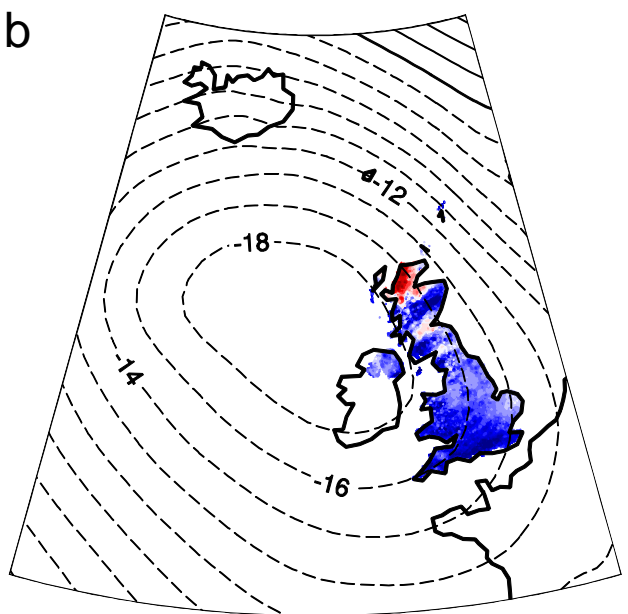

d
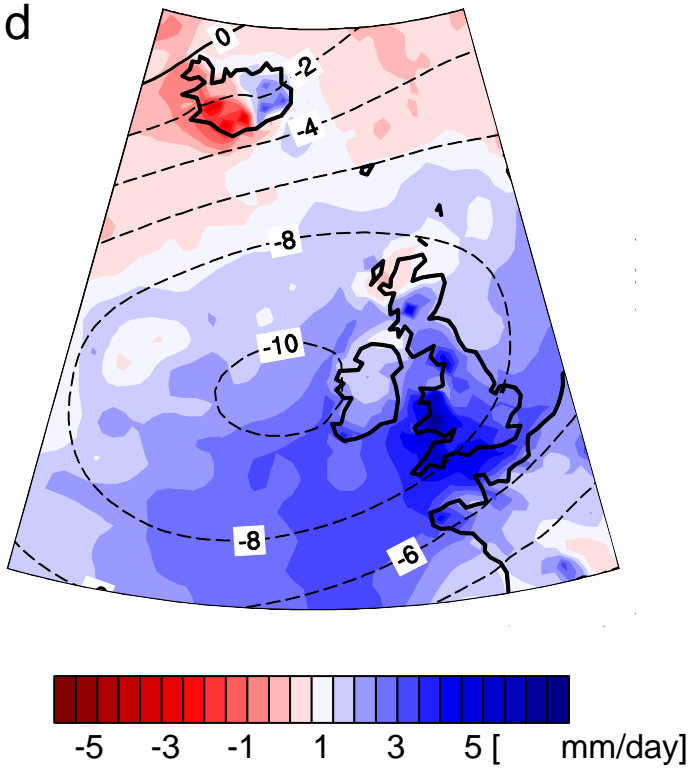

Figure 1: Precipitation ${ }^{34}$ (colours, in $\mathrm{mm}$ day-1) and mean sea level pressure ${ }^{11}$ (contours, in $\mathrm{hPa}$ ) as observed for January 2014 absolute values in a and as anomalies from the observed 1981-2010 climatology in $\mathbf{b}$, and in the wettest $1 \%$ of the Actual Conditions ensemble as absolute values in $\mathbf{c}$ and as anomalies from the model 1986-2011 climatology in $\mathbf{d}$. 

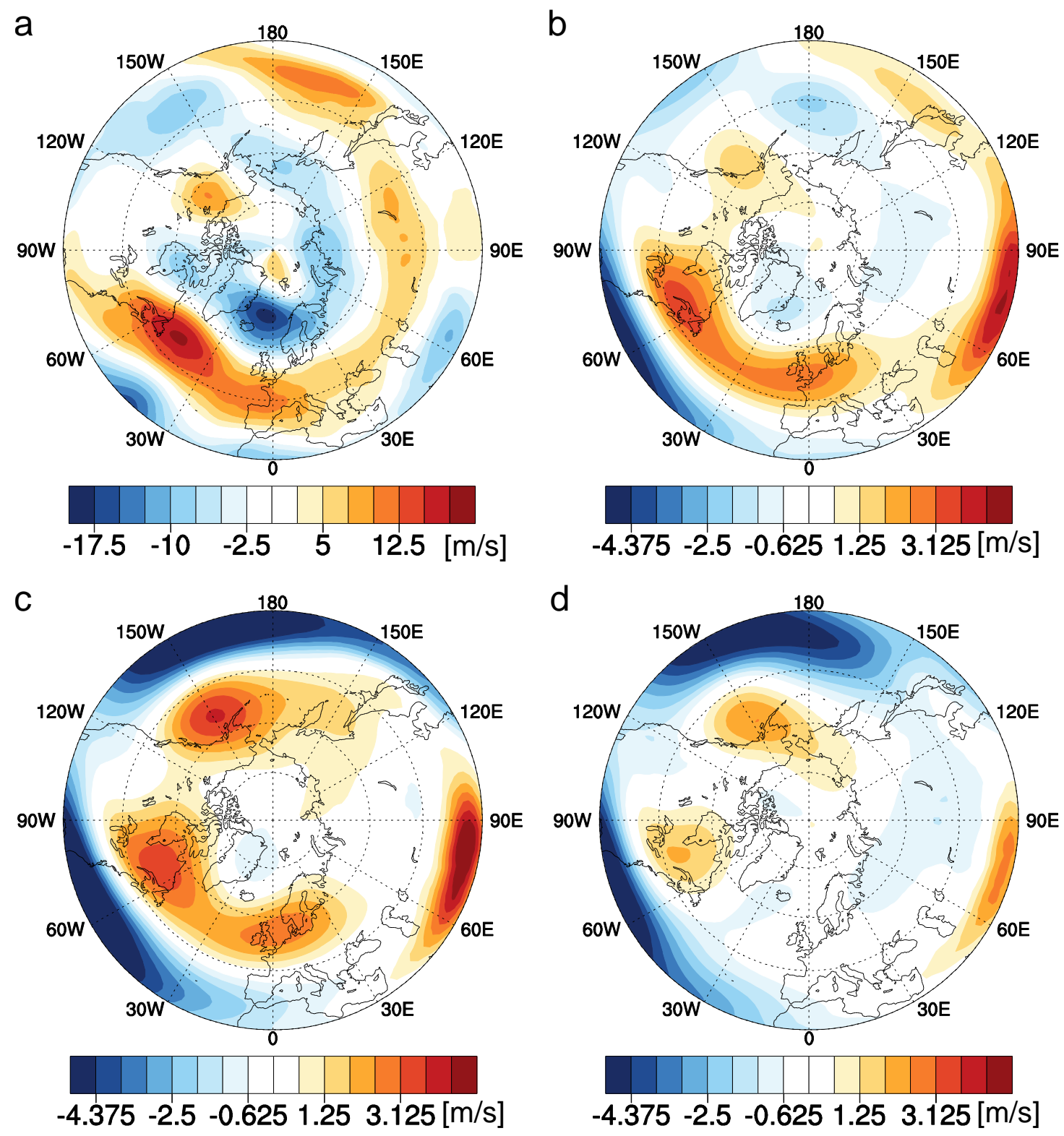

378 Figure 2: Anomalies of zonal wind at $200 \mathrm{hPa}$ for January 2014 a in ERA-interim ${ }^{11}$, relative to the 1986-

3792011 ERA-interim climatology, and $\mathbf{b}$ in the ensemble mean of the Actual Conditions simulations,

380 relative to the model 1986-2011 climatology. $\mathbf{c}$ and $\mathbf{d}$, as $\mathbf{b}$, but for the ensemble means of the Natural

381 simulations with the HadGEM2-ES and CCSM4 models respectively. 

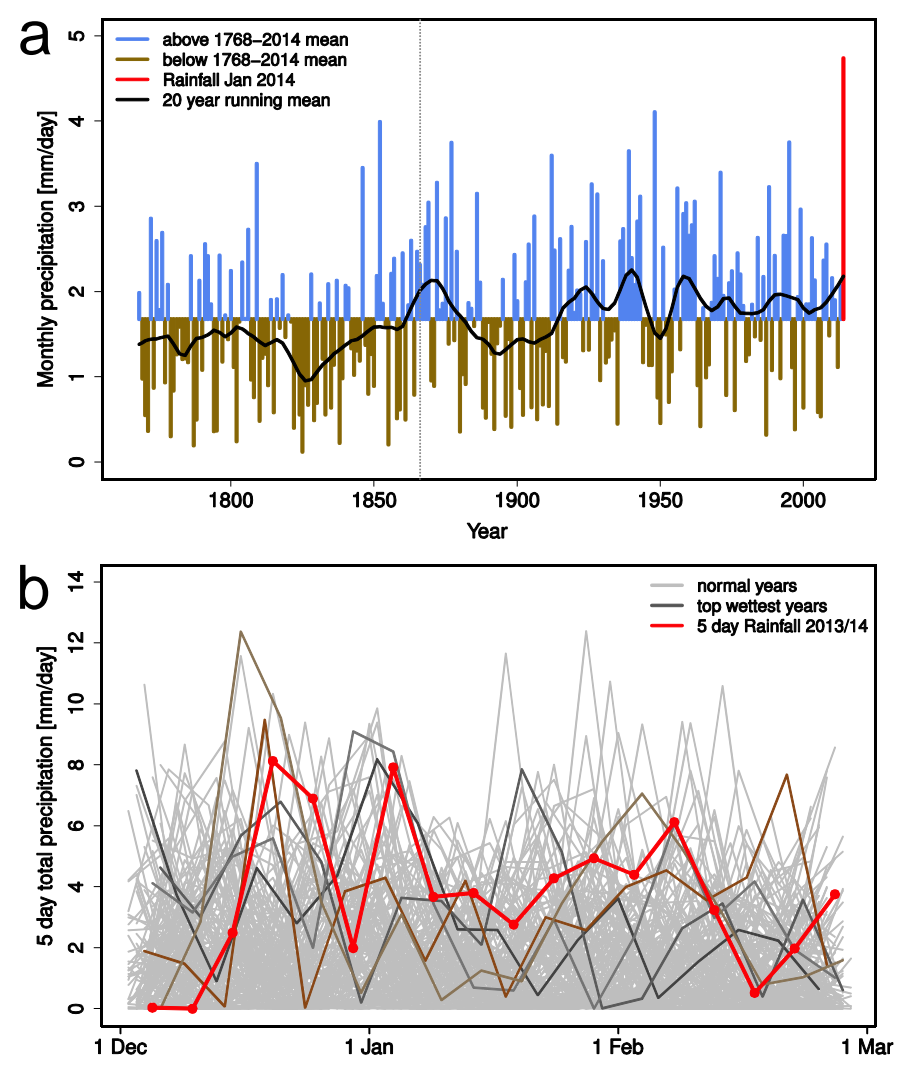

Figure 3: a Time series of monthly mean rain/precipitation for January 1768-2014 at the Radcliffe Observatory, Oxford. Above/below overall average values are plotted in blue/brown. January 2014 is highlighted in red. The black line is the 20 -year Lowess-smoothed monthly mean precipitation. The measurements are rain only until around 1867 (dotted thin vertical line), but include snow since then. $\mathbf{b}$ Comparison of all the 5-day mean precipitation for all winter months from 1827/28-2013/14. The 5 wettest years are highlighted in dark grey. Winter 2013/14 is plotted in red. 

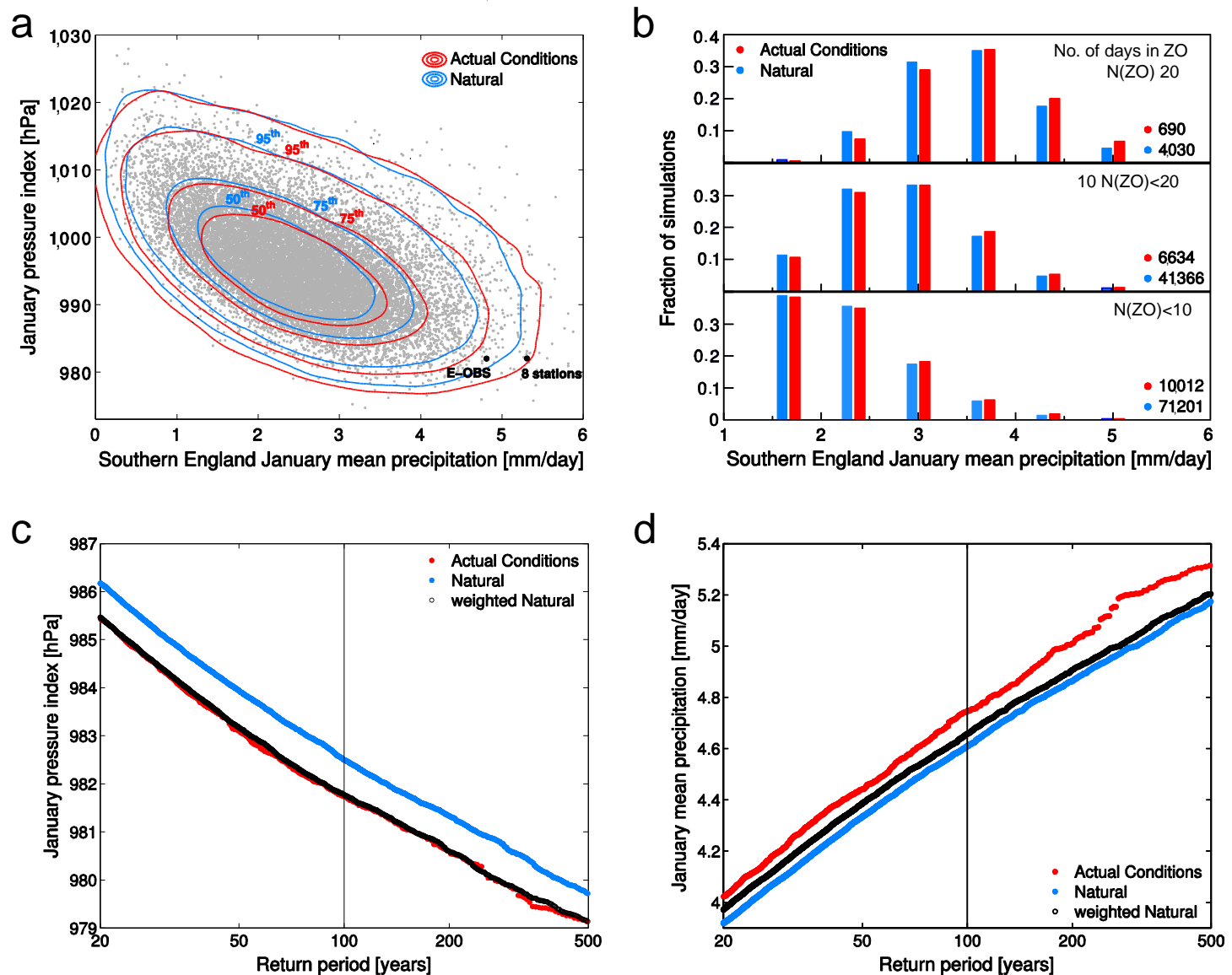

Figure 4: a Relationship between modelled January monthly average Southern England precipitation and mean sea level pressure at $20^{\circ} \mathrm{W}, 60^{\circ} \mathrm{N}$. The $50^{\text {th }}, 75^{\text {th }}, 95^{\text {th }}$ and $99^{\text {th }}$ percentiles of the distribution of the Actual Conditions and all Natural simulations are estimated using a Gaussian bivariate kernel density estimator. Grey dots represent January averages for each individual Actual Conditions simulations and the black dots show values from observations (" 8 stations" refers to the average of 8 stations in Southern England for the precipitation index and the NCEP reanalysis ${ }^{35}$ for the pressure index, "E-OBS" refers to the same definition as the modelled precipitation index using the gridded $E$ OBS dataset ${ }^{36}$ also with NCEP pressure index). The Actual Conditions and Natural joint distributions are significantly different at the 0.05 level based on a two-sided bivariate version of the Kolmogorov-Smirnov test $^{37}$. b As a but showing the relationship between modelled January Southern England precipitation binned in 7 categories and the January ZO index binned in three categories of number of days per month. For all three categories, the distributions of Actual Conditions and Natural are statistically different at the 0.05 level, according to both a two-sided Kolmogorov-Smirnov and a two-sided Cramervon Mises test. The number of ensemble members in each of the three categories is given on the bottom-right corner of each sub-panel. c Return periods for pressure for the Actual Conditions and pooled Natural simulations along with pooled Natural weighted to make its pressure values match the Actual Conditions simulation. $\mathbf{d}$ as $\mathbf{c}$ but for precipitation, using the same weights as in $\mathbf{c}$. 
a

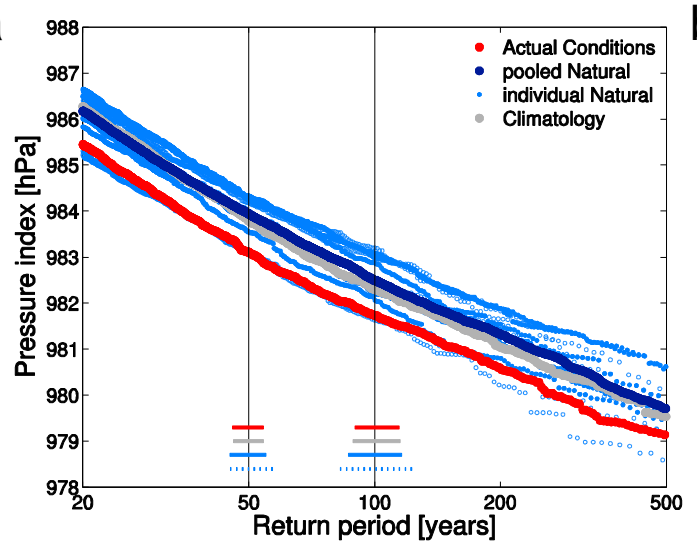

C

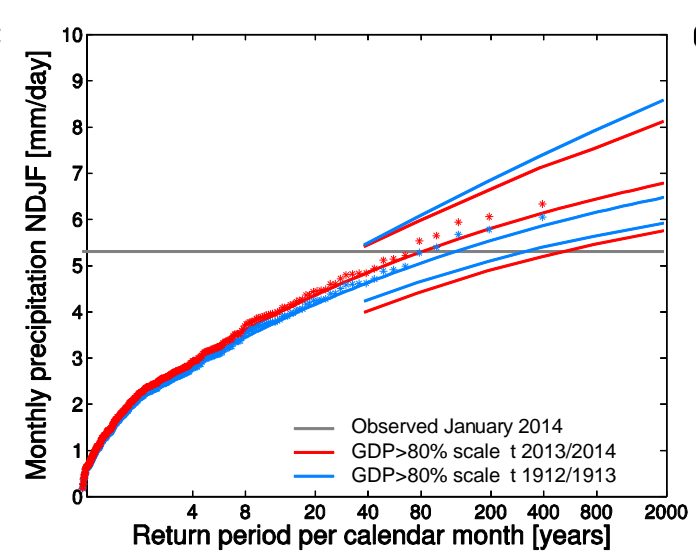

e

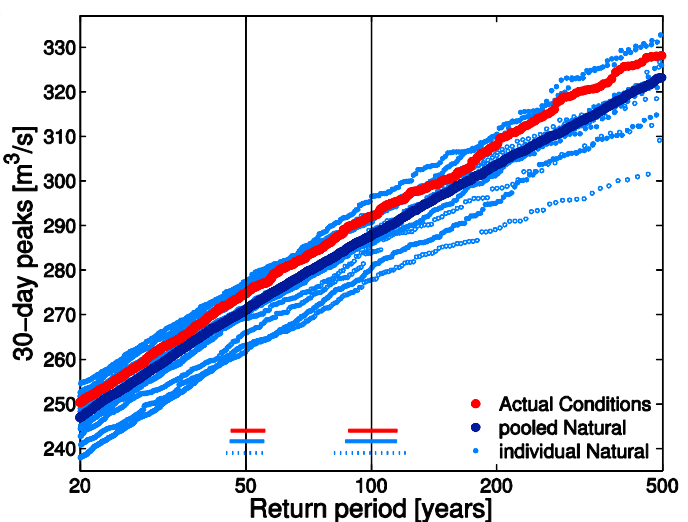

b

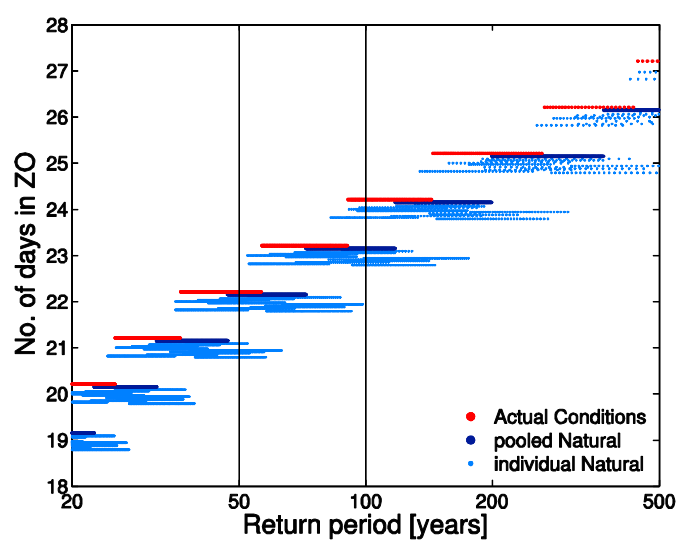

d

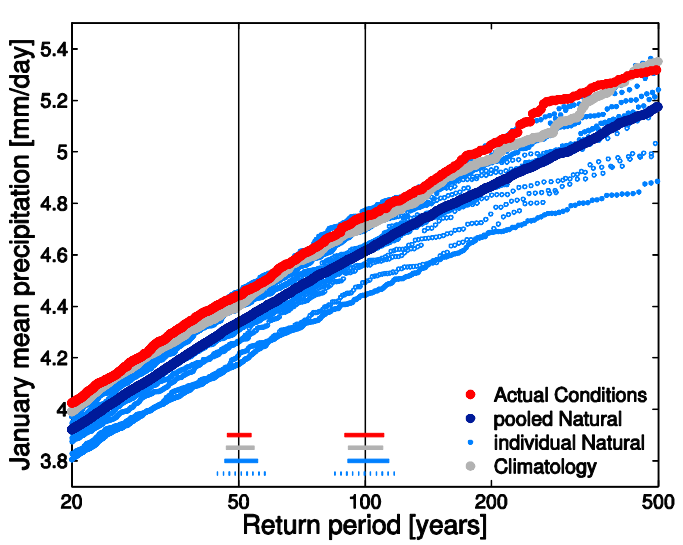

Figure 5: Return periods for a modelled January pressure index (each dot represents an ensemble member) with 5-95\% confidence intervals for 1-in-50-year events and 1-in-100-year events in Actual Conditions estimated by resampling the distribution 100 times, represented as horizontal lines. Red represents Actual Conditions simulations, grey a similar ensemble but for 1986-2011 (the model climatology), dark blue the pooled Natural simulations, and light blue individual Natural (sub-) ensembles, with solid circles for the 6 of the 11 Natural ensembles with around 15,000 simulations, and empty circles for the other 5 with around 7,000 simulations. Only four 5-95\% confidence intervals for 1 in-50-year events and 1-in-100-year events (red: Actual Conditions, grey: Climatology, light blue: Natural ensembles with around 15,000 ensemble members and dashed light blue: Natural ensembles with around 7,000 simulations) are shown because the confidence intervals represent only the sampling uncertainty, not the uncertainty in the estimation of the model simulations. $\mathbf{b}$ as $\mathbf{a}$ but modelled 
frequency of the ZO regime. No confidence intervals are shown due to the categorical nature of return values. c observed monthly precipitation averaged for 8 stations across Southern England for the months of November to February individually for the years 1912-2013 fitted to a Generalised Pareto Distribution with location and scale parameters linearly dependent on the low-pass filtered global mean temperature. Red lines indicate the fit and 90\% confidence interval for the current temperature (2013/2014), blue for a temperature representative of pre-industrial conditions (1912/1913). The red (blue) crosses show the observations shifted up (down) to these years using the fitted trend. The horizontal grey line represents the observed value for January 2014. The fit has been performed for monthly means of four calendar months to increase the sample size, the return period is given per month for comparison with the other results. $\mathbf{d}$ as a for modelled January mean precipitation in Southern England, $\mathbf{e}$ as a for modelled 30-day peak flows for the Thames at Kingston, and $\mathbf{f}$ difference between the Natural and the Actual Conditions simulations in number of properties individually at risk of flooding with annual probability $1 / T$, where $T$ is the return period.

\section{References}

1 Huntingford, C. et al. Potential influences on the United Kingdom's floods of winter 2013/14. Nature Climate Change 4, 769-777, doi:10.1038/nclimate2314 (2014).

2 Matthews, T., Murphy, C., Wilby, R. L. \& Harrigan, S. Stormiest winter on record for Ireland and UK. Nature Climate Change 4, 738-740 (2014).

$3 \quad$ Pall, P. et al. Anthropogenic greenhouse gas contribution to flood risk in England and Wales in autumn 2000. Nature 470, 382-385 (2011).

4 Association of British Insurers, https://www.abi.org.uk/Insurance-and-savings/Topicsand-issues/Flooding/2014-floods-in-numbers (Accessed September 2015)

5 Association of British Insurers, https://www.abi.org.uk/News/Newsreleases/2010/11/massive-rise-in-britains-flood-damage-bill-highlights-the-need-formore-help-for-flood-vulnerable-communities-says-the-abi.aspx (Accessed September 2015)

6 http://www.bbc.co.uk/news/uk-politics-25656426

7 Stott, P. A., Stone, D. A. \& Allen, M. R. Human contribution to the European heatwave of 2003. Nature 432, 610-614, doi:10.1038/nature03089 (2004).

8 Kay, A. L., Crooks, S. M., Pall, P. \& Stone, D. A. Attribution of Autumn/Winter 2000 flood risk in England to anthropogenic climate change: A catchment-based study. Journal of Hydrology 406, 97-112, doi:10.1016/j.jhydrol.2011.06.006 (2011).

9 Massey, N. et al. weather@home - development and validation of a very large ensemble modelling system for probabilistic event attribution. Quarterly Journal Of The Royal Meteorological Society, doi:10.1002/qj.2455 (2014).

10 Taylor, K. E., Stouffer, R. J. \& Meehl, G. A. An Overview of CMIP5 and the Experiment Design. Bull. Amer. Meteorol. Soc. 93, 485-498 (2012).

11 Dee, D. P. et al. The ERA-Interim reanalysis: configuration and performance of the data assimilation system. Quarterly Journal of the Royal Meteorological Society 137, 553-597 (2011).

12 van Haren, R., van Oldenborgh, G. J., Lenderink, G. \& Hazeleger, W. Evaluation of modeled changes in extreme precipitation in Europe and the Rhine basin. Environ. Res. Lett. 8, 7, doi:10.1088/1748-9326/8/1/014053 (2013).

13 van Haren, R., van Oldenborgh, G. J., Lenderink, G., Collins, M. \& Hazeleger, W. SST and circulation trend biases cause an underestimation of European precipitation trends. Climate Dynamics 40, 1-20, doi:10.1007/s00382-012-1401-5 (2013). 
14 Vautard, R. Multiple weather regimes over the North Atlantic - Analysis of precursors and successors. Mon. Weather Rev. 118, 2056-2081, doi:10.1175/15200493(1990)118<2056:mwrotn>2.0.co;2 (1990).

15 Michelangeli, P. A., Vautard, R. \& Legras, B. Weather regimes - Reccurence and quasi stationarity. J. Atmos. Sci. 52, 1237-1256, doi:10.1175/15200469(1995)052<1237:wrraqs>2.0.co;2 (1995).

16 Yiou, P., Goubanova, K., Li, Z. X. \& Nogaj, M. Weather regime dependence of extreme value statistics for summer temperature and precipitation. Nonlinear Process Geophys. 15, 365-378 (2008).

17 Barnes, E. A. \& Polvani, L. Response of the Midlatitude Jets, and of Their Variability, to Increased Greenhouse Gases in the CMIP5 Models. Journal of Climate 26, 71177135 (2013).

18 Zappa, G., Hoskins, B. J. \& Shepherd, T. G. Improving Climate Change Detection through Optimal Seasonal Averaging: The Case of the North Atlantic Jet and European Precipitation. Journal of Climate 28 (16) (2015).

19 Cattiaux, J. \& Cassou, C. Opposite CMIP3/CMIP5 trends in the wintertime Northern Annular Mode explained by combined local sea ice and remote tropical influences. Geophysical Research Letters 40 (2013).

20 Rodwell, M. J., Rowell, D. P. \& Folland, C. K. Oceanic forcing of the wintertime North Atlantic Oscillation and European climate. Nature 398, 320-323, doi:10.1038/18648 (1999).

21 Haarsma, R. J., Selten, F. \& van Oldenborgh, G. J. Anthropogenic changes of the thermal and zonal flow structure over Western Europe and Eastern North Atlantic in CMIP3 and CMIP5 models. Climate Dynamics 41, 2577-2588, doi:10.1007/s00382013-1734-8 (2013).

22 Crooks, S. M. \& Naden, P. S. CLASSIC: a semi-distributed rainfall-runoff modelling system. Hydrol. Earth Syst. Sci. 11, 516-531 (2007).

23 Marsh, T. \& Harvey, C.L. 2012. The Thames flood series: a lack of trend in flood magnitude and a decline in maximum levels. Hydrology Research, 43(3), 203-214

24 Bradbrook, K., Waller, S., \& Morris, D. National floodplain mapping: Datasets and methods - 160,000 km in 12 months. Natural Hazards, 36(1-2), 103-123 (2005).

25 Trenberth, K., Fasullo, J. T. \& Shepherd, T. G. Attribution of climate extreme events. Nature Climate Change 5, 725-730, doi:10.1038/nclimate2657 (2015).

26 Hansen, J., Sato, M. \& Ruedy, R. Perception of climate change. PNAS 109 (37), E2415-2423, doi:10.1073/pnas.1205276109 (2012).

27 Crichton D. Flood Risk and Insurance in England and Wales: Are there lessons to be learned from Scotland? (Benfield Hazard Research Centre, UCL, London, 2005).

28 Committee on Climate Change. Managing climate risks to well-being and the economy. (Adaptation Sub-Committee Progress Report, Committee on Climate Change, London, 2014). http://www.theccc.org.uk/wpcontent/uploads/2014/07/Final_ASC-2014_web-version-4.pdf (Accessed September 2015)

29 Environment Agency. Flood and coastal erosion risk management. (Long-term investment scenarios, Report No. LIT10045, Environment Agency, Bristol UK, 2014). https://www.gov.uk/government/uploads/system/uploads/attachment_data/file/381939 /FCRM_Long_term_investment_scenarios.pdf (Accessed September 2015)

30 Kay, A. L., Davies, H. N., Bell, V. A. \& Jones, R. G. Comparison of uncertainty sources for climate change impacts: flood frequency in England. Climatic Change 92, 41-63, doi:10.1007/s10584-008-9471-4 (2009).

31 James, R. et al. Characterizing loss and damage from climate change. Nature Clim. Change 4, 938-939, doi:10.1038/nclimate2411 (2014).

32 Cramer, W. et al. in Climate Change 2014: Impacts, Adaptation, and Vulnerability. Part A: Global and Sectoral Aspects. Contribution of Working Group II to the Fifth Assessment Report of the Intergovernmental Panel on Climate Change (eds C. B. Field et al.) (Cambridge University Press, 2014). 
$52233 \quad$ Bindoff, N. L. et al. in Climate Change 2013: The Physical Science Basis. Contribution of Working Group I to the Fifth Assessment Report of the Intergovernmental Panel on Climate Change (eds T. F. Stocker et al.) (Cambridge University Press, 2013).

34 Perry, M. \& Hollis, D. The generation of monthly gridded datasets for a range of climatic variables over the UK. Int. J. Climatol. 25, 1041-1054, doi:10.1002/joc.1161 (2005).

35 Kistler, R. et al. The NCEP-NCAR 50-year reanalysis: Monthly means CD-ROM and documentation. Bull. Amer. Meteorol. Soc. 82, 247-267, doi:10.1175/15200477(2001)082<0247:tnnyrm>2.3.co;2 (2001).

36 Haylock, M. R. et al. A European daily high-resolution gridded data set of surface temperature and precipitation for 1950-2006. J. Geophys. Res.-Atmos. 113, D20119D20119 (2008).

37 Peacock, J. A. Two-dimensional goodness-of-fit testing in astronomy. Mon. Not. Roy. Astron. Soc. 202, 615-627 (1983). 


\section{Supplementary Information:}

\section{Human influence on climate in the 2014 Southern England winter floods and their impacts}

Nathalie Schaller, Alison L. Kay, Rob Lamb, Neil R. Massey, Geert Jan van Oldenborgh, Friederike E. L. Otto, Sarah N. Sparrow, Robert Vautard, Pascal Yiou, lan Ashpole, Andy Bowery, Susan M. Crooks, Karsten Haustein, Chris Huntingford, William J. Ingram, Richard G. Jones, Tim Legg, Jonathan Miller, Jessica Skeggs, David Wallom, Antje Weisheimer, Simon Wilson, Peter A. Stott \& Myles R. Allen

\section{Observational evidence}

\subsection{Precipitation}

The winter 2013/2014 precipitation set a record for several rain gauge stations in Southern England. Supplementary Fig. 1 shows the location and time series of 14 stations with long-term observations. The 8 series with observations since at least 1912 are averaged to give a regional precipitation index. The daily station data were extracted from the UK Met. Office digital archives. Particularly noteworthy are the extremely high values in 2013/2014 at some sites in the Thames basin, and the range of values across stations, which is wider than the second highest value since 1912 (in 1913/1914). 

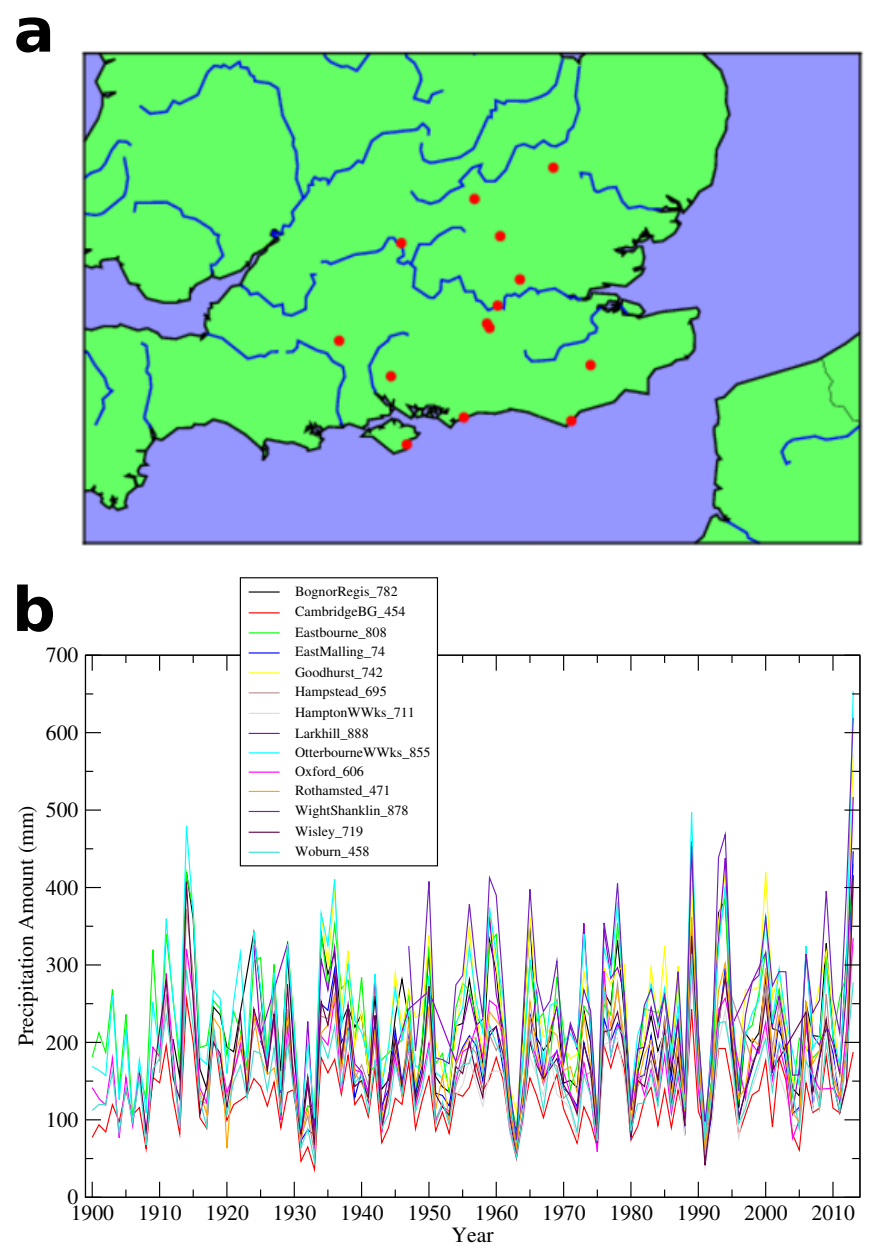

Supplementary Figure 1: a Location of the 14 rain gauges in Southern England. b Time series of seasonal (DJF) rain amount for each gauge. For 8 gauges, time series are available since 1912 and these 8 time series are averaged to produce the observed precipitation index defined in the main text.

\subsection{Sea level pressure}

Sea level pressure (SLP) was persistently low northwest of Scotland during winter 2013/2014, implying south-westerly flows over Southern England. To characterize this SLP anomaly and such south-westerly flow, we define a simple index, the SLP value at $20^{\circ} \mathrm{W}$ and $60^{\circ} \mathrm{N}$. Supplementary Fig. 2 shows time series of monthly and seasonal averages of this index for winter. The seasonal mean SLP had a record low in 2013/2014, and the January mean was second lowest on record, in both the National Center for Environmental Prediction $\left(\mathrm{NCEP}^{1}\right)$ and $20 \mathrm{CR}^{2}$ reanalyses, starting in 1948 and 1871 respectively. However neither the SLP nor precipitation series have a trend significant at the $95 \%$ level over the 144 years of 20CR (using a Student's $t$-test). 
a
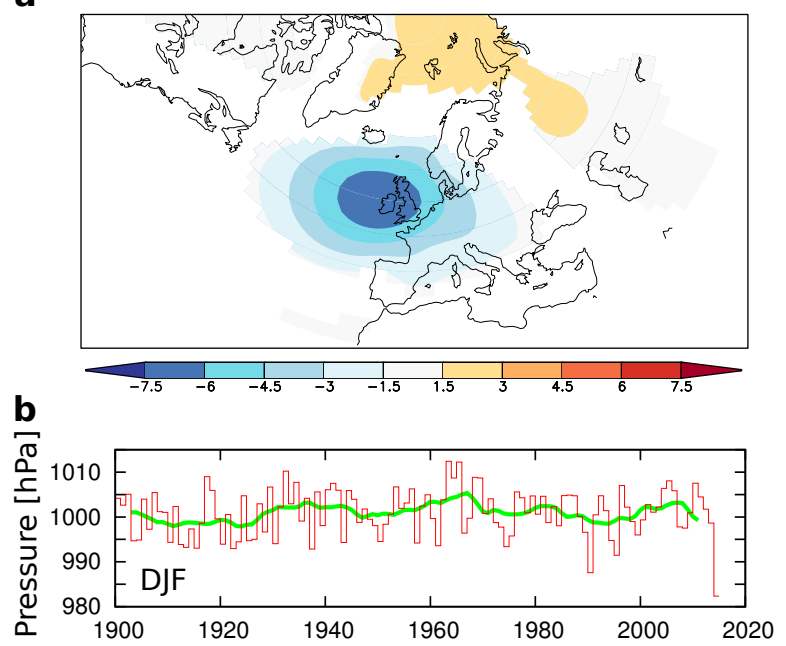

C

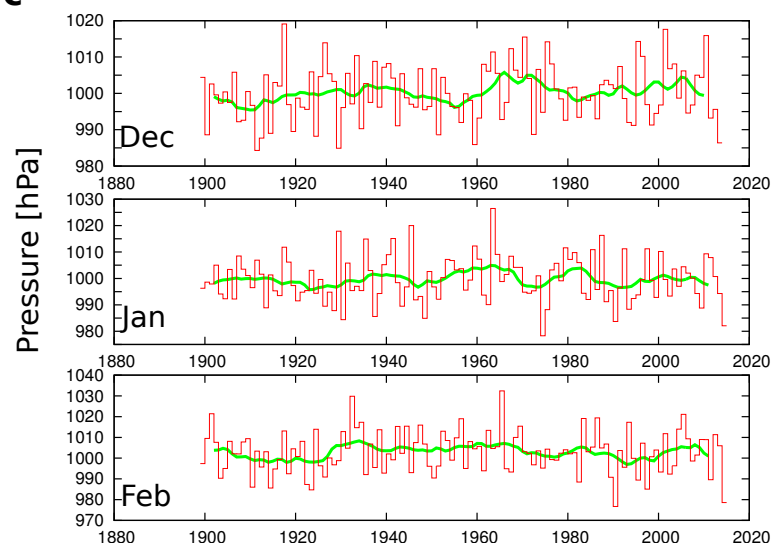

e

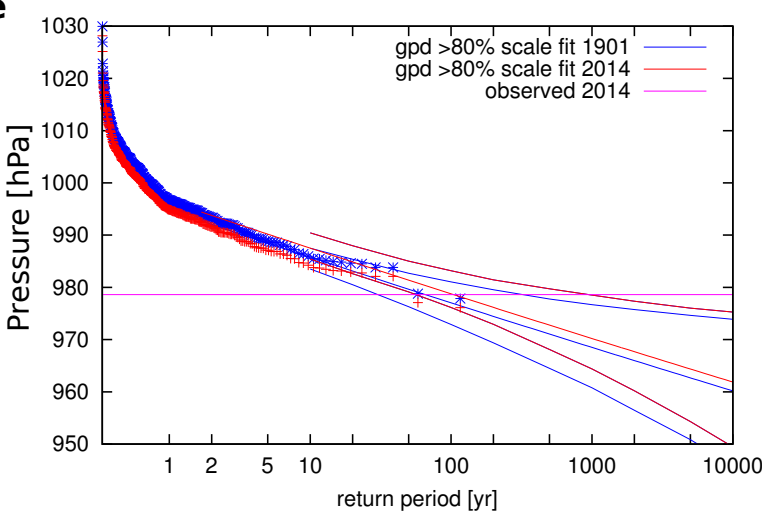

Supplementary Figure 2: a Regression of summed DJF precipitation for 8 gauges shown in Supplementary Fig. 1 on DJF SLP ${ }^{3}$ for $1912-2010$. b Time series of DJF SLP at $60^{\circ} \mathrm{N}, 20^{\circ} \mathrm{W}$. c Time series of December, January and February SLP at $60^{\circ} \mathrm{N}, 20^{\circ} \mathrm{W}$. d Extreme value fit of DJF average SLP at $60^{\circ} \mathrm{N}, 20^{\circ} \mathrm{W}$ in the years $1901-$ 2013 extrapolated to $2013 / 2014$ (red crosses and the red lines for the current climate correspond to the $90 \%$ confidence interval estimated with a non-parametric bootstrap, blue crosses and lines represent the same but in the climate of 1901, and the horizontal pink line represents the observed value for DJF 2013/2014). e Same as $\mathbf{d}$ but for all winter months separately against the observed value in January 2014.

\section{Climate model experiment setup and validation}

Perturbed initial-conditions simulations performed with the citizen science global and nested regional climate modelling project weather@home are obtained by applying a difference derived from one-day differences in potential temperature from a single year-long integration of the global model. The regional climate model (RCM), HadRM3P, is nested in the atmosphere-only general circulation model (AGCM) HadAM $3 \mathrm{P}^{4}$. The spatial domain of the RCM is roughly rectangular, with the coordinates of its corners given in Supplementary Table 1. 
Supplementary Table 1: Coordinates of the spatial domain of the RCM.

\begin{tabular}{lll}
\hline & Longitude & Latitude \\
\hline Top left & $53.7^{\circ} \mathrm{W}$ & $59.9^{\circ} \mathrm{N}$ \\
Top right & $76.5^{\circ} \mathrm{E}$ & $67.1^{\circ} \mathrm{N}$ \\
Bottom right & $38.5^{\circ} \mathrm{E}$ & $21.0^{\circ} \mathrm{N}$ \\
Bottom left & $11.5^{\circ} \mathrm{W}$ & $17.7^{\circ} \mathrm{N}$ \\
\hline
\end{tabular}

In the Actual Conditions experiment, the AGCM uses observed sea surface temperature (SST) data from 1 December 2013 until 15 February 2014 from the Operational Sea Surface Temperature and Sea Ice Analysis (OSTIA) dataset ${ }^{5,6}$ and present day atmospheric composition (well-mixed greenhouse gases, ozone and reflective sulphate aerosols) ${ }^{4}$ to simulate weather events consistent with the observed climate boundary conditions. The simulations were set up at the end of February 2014 when no SST and sea-ice data was available for the last two weeks of February. Therefore the modelled last two weeks of February are driven with the average of 10-15 February 2014. For the Natural experiments, 11 estimates of the changes in SST patterns due to anthropogenic forcing have been subtracted from the observed 2013/2014 SSTs used for the Actual Conditions simulations, and preindustrial atmospheric composition is specified ${ }^{7}$. Thus they simulate the winter 2013/2014 in 11 counterfactual worlds with no human influence.

The estimated anthropogenic changes in SST we subtract are based on 11 coupled general circulation models (GCM) simulations from the Coupled Model Intercomparison Project phase 5 (CMIP5) archive ${ }^{8}$. We use the "Historical" simulations (which include both anthropogenic and natural forcings, the latter from volcanoes and solar fluctuations, for 1850-2005) and the "HistoricalNat" simulations (which include only natural forcings for the same period). We selected all 11 GCMs that had more than 3 ensemble members for both these experiments in the CMIP5 archive. For each model and experiment, we average the monthly climatologies over all ensemble members available, and for 1996-2005 i.e. the last decade available, and then subtract those of HistoricalNat from those of Historical. The resulting anomaly patterns thus represent 11 estimates of the impact on SSTs of human 
activity. They are shown in Supplementary Fig. 3 for the month of January, and referred to as Delta SSTs.
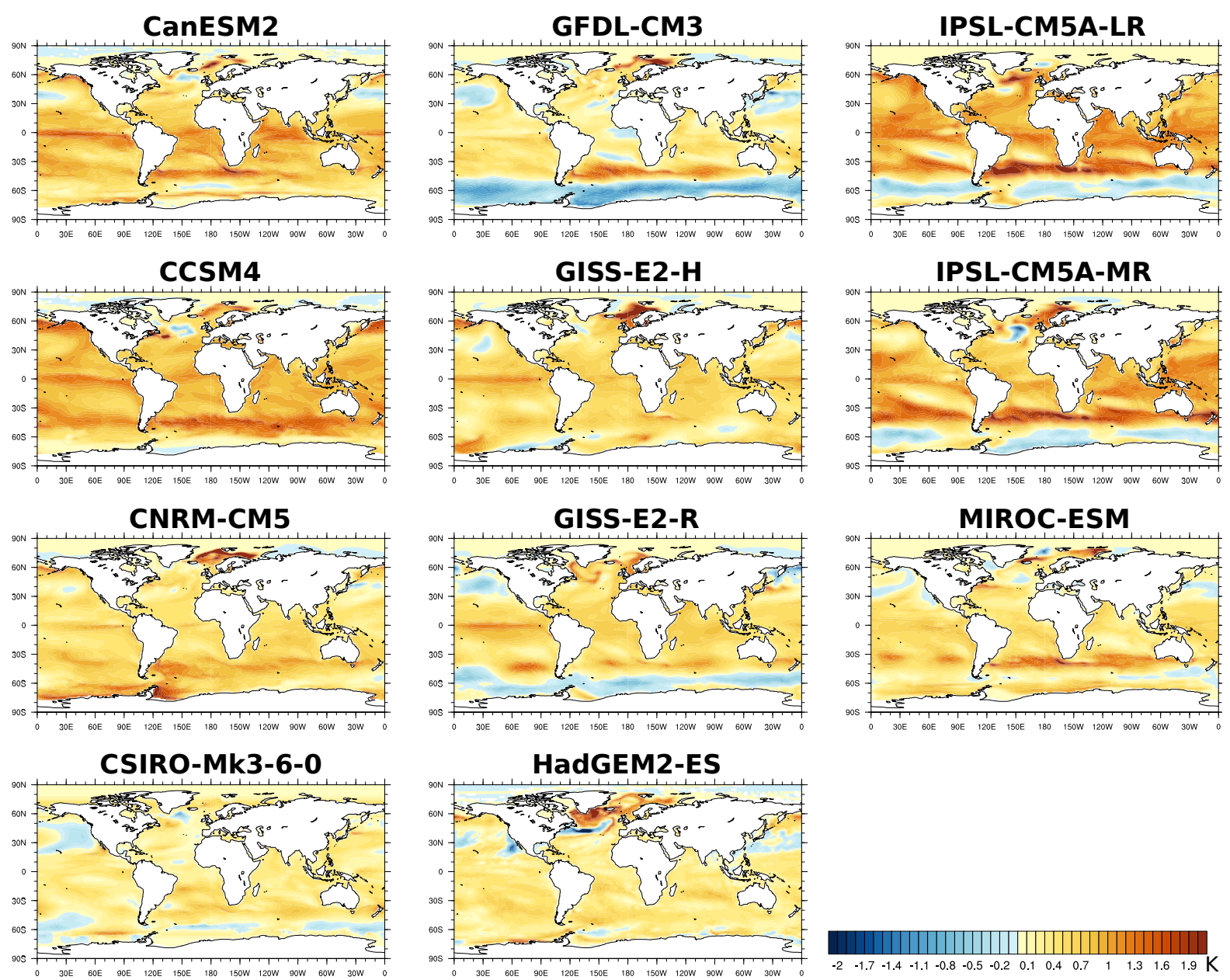

Supplementary Figure 3: January SST response pattern to anthropogenic forcing from the 11 CMIP5 models used).

To assess the sampling error in the Delta SSTs, Fig S4 shows them divided by the standard deviation of the Historical ensemble members for the two GCMs that give the most different response of Southern England precipitation, CCSM4 and HadGEM2-ES. Using the standard deviation between the ensemble members of the HistoricalNat simulations gives similar results (not shown). CCSM4 has a generally strong response pattern (Supplementary Fig. 3d), with Delta SST typically at least three times the standard deviation. However, HadGEM2-ES has a generally smaller response pattern (Supplementary Fig. 3k), and the apparent signal is comparable to the standard deviation in many places. 

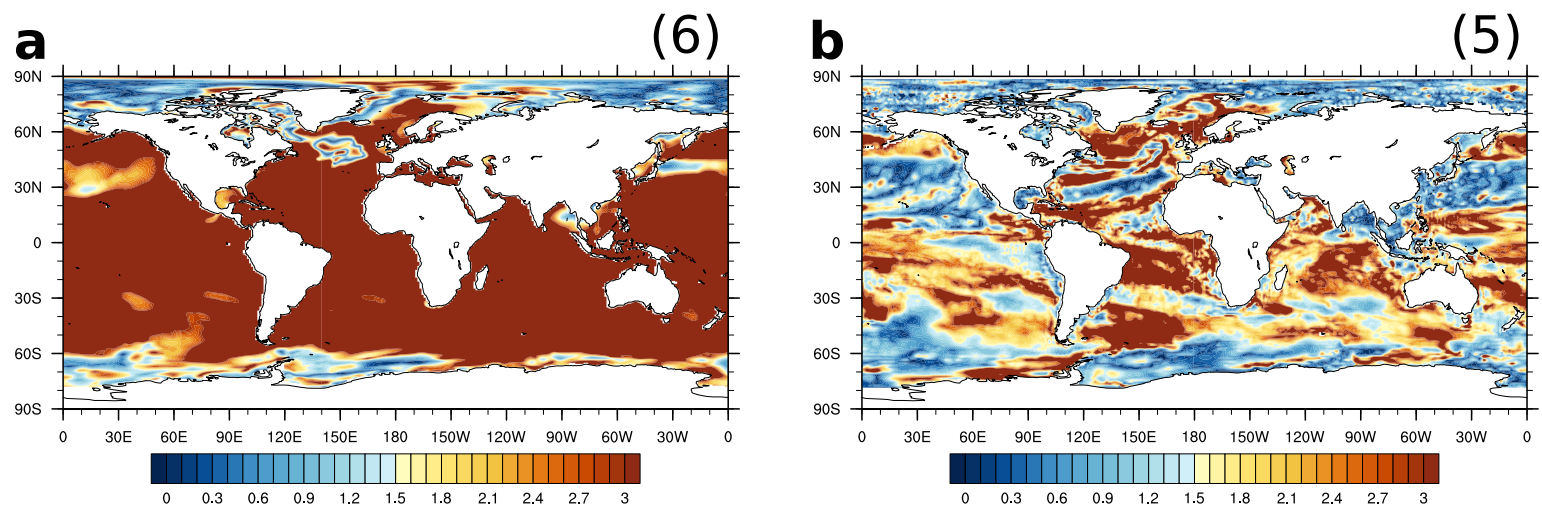

Supplementary Figure 4: Ratio of the Delta SSTs to standard deviation between the ensemble members available for a) CCSM4 Historical and b) HadGEM2-ES Historical, with the number of ensemble members indicated in the top right corner in brackets.

To assess the sensitivity of our results to the uncertain specification of sea ice in the Natural simulations, an additional ensemble uses 2013/2014 SSTs and atmospheric composition but the sea ice conditions from the Natural simulations. Supplementary Fig. 5 shows no significant effect on the probability of the 1-in-100-year event for January precipitation in Southern England. The changes in risk caused by anthropogenic forcings identified in this study are therefore mainly due to changed SSTS.

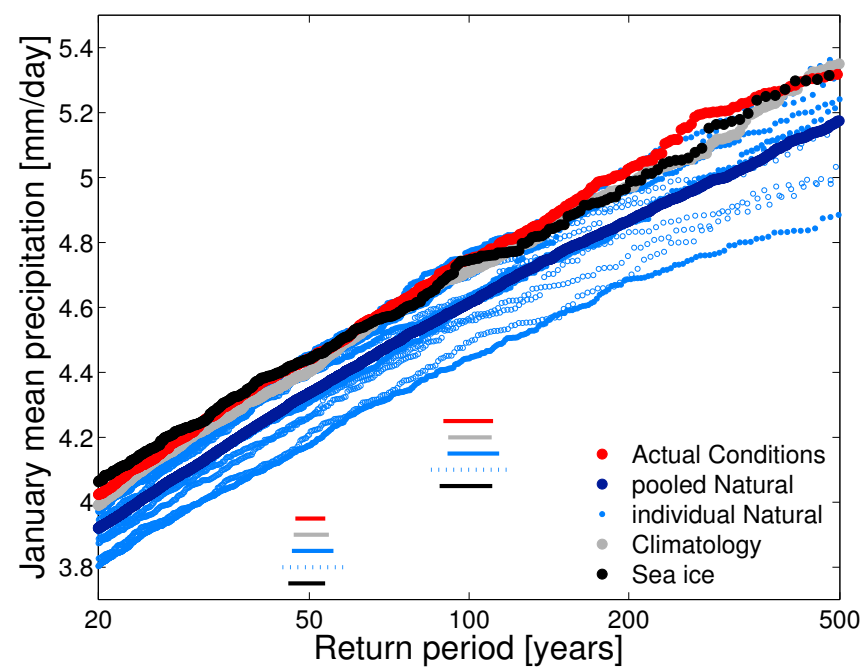

Supplementary Figure 5: Return periods for modelled January mean precipitation in Southern England. Each dot represents an ensemble member, with 5-95\% confidence intervals for 1-in-50-year and 1-in-100-year events in Actual Conditions, estimated by resampling the distribution 100 times, represented as horizontal lines. Red represents the Actual Conditions ensemble, dark blue the pooled Natural ensembles, and light blue individual Natural ensembles, with solid circles for 6 of the 11 Natural ensembles with around 15,000 members, and empty circles for the other 5 with around 7,000 members, grey a similar ensemble to Actual Conditions but for 1986- 
2011 (the model climatology), and black for the ensemble with SSTs and atmospheric gas concentrations from Actual Conditions but sea ice extent from Natural. Only five 5-95\% confidence intervals for 1-in-50-year events and 1-in-100-year events (colours as before) are shown because the confidence intervals only represent the sampling uncertainty, not the physical uncertainty.

Supplementary Table 2 summarizes the three types of experiments performed, along with further information about the forcings used and the number of simulations returned. The climatology used to calculate the anomalies in Fig. 1d, Figs 2b-d and shown in Fig. 5a and Fig. 5d is a weather@home perturbed-initial-conditions ensemble with SSTs and sea ice extent prescribed from the OSTIA dataset for December 1985-November 2011 and with observed atmospheric composition. Around 900 simulations are available for each year.

Initially, around 8,000 simulations were submitted for each of the 11 Natural experiments. With the storage capacity available limited, not all Natural ensembles could have as many members as the Actual Conditions ensemble. 6 Natural experiments were then increased in size (based on the CCSM4, GFDL-CM3, GISSE2-H, HadGEM2-ES, IPSL-CM5A-MR and MIROC-ESM Delta SSTs, see Supplementary Table 2), chosen because they were well-distributed across the range of 1-in-100-year precipitation response, and because they were from different modelling centres. 
Supplementary Table 2: Summary of the number of experiments performed and boundary conditions used. There are 134,354 simulations in total, of which 116,987 are Natural ones (e-o).

\begin{tabular}{|c|c|c|c|c|}
\hline $\begin{array}{l}\text { Ensemble } \\
\text { letter }\end{array}$ & Applied SSTs & $\begin{array}{l}\text { Size of } \\
\text { ensemble }\end{array}$ & $\begin{array}{l}\text { Atmospheric } \\
\text { GHG } \\
\text { concentrations }\end{array}$ & Sea ice conditions \\
\hline $\mathbf{a}$ & 2013/2014 SSTs & 17,367 & $2013 / 2014$ & $2013 / 2014$ \\
\hline C & 2013/2014 SSTs & 9,067 & $2013 / 2014$ & $\begin{array}{l}\text { Maximum extent } \\
\text { Northern Hemisphere: 1986/1987 } \\
\text { Southern Hemisphere: } 2007 / 2008\end{array}$ \\
\hline e & $\begin{array}{l}2013 / 2014 \text { SSTs - } \\
\text { CanESM2 } \\
\text { anthropogenic pattern }\end{array}$ & 7,243 & Pre-industrial & $\begin{array}{l}\text { Maximum extent } \\
\text { Northern Hemisphere: } 1986 / 1987 \\
\text { Southern Hemisphere: } 2007 / 2008\end{array}$ \\
\hline f & $\begin{array}{l}2013 / 2014 \text { SSTs - } \\
\text { CCSM4 anthropogenic } \\
\text { pattern }\end{array}$ & 13,989 & Pre-industrial & $\begin{array}{l}\text { Maximum extent } \\
\text { Northern Hemisphere: 1986/1987 } \\
\text { Southern Hemisphere: } 2007 / 2008\end{array}$ \\
\hline g & $\begin{array}{l}2013 / 2014 \text { SSTs - } \\
\text { CNRM-CM5 } \\
\text { anthropogenic pattern }\end{array}$ & 7,394 & Pre-industrial & $\begin{array}{l}\text { Maximum extent } \\
\text { Northern Hemisphere: 1986/1987 } \\
\text { Southern Hemisphere: } 2007 / 2008\end{array}$ \\
\hline $\mathbf{h}$ & $\begin{array}{l}2013 / 2014 \text { SSTS - } \\
\text { CSIRO-Mk3-6-0 } \\
\text { anthropogenic pattern }\end{array}$ & 7,595 & Pre-industrial & $\begin{array}{l}\text { Maximum extent } \\
\text { Northern Hemisphere: 1986/1987 } \\
\text { Southern Hemisphere: } 2007 / 2008\end{array}$ \\
\hline i & $\begin{array}{l}2013 / 2014 \text { SSTs - } \\
\text { GFDL-CM3 } \\
\text { anthropogenic pattern }\end{array}$ & 15,726 & Pre-industrial & $\begin{array}{l}\text { Maximum extent } \\
\text { Northern Hemisphere: 1986/1987 } \\
\text { Southern Hemisphere: } 2007 / 2008\end{array}$ \\
\hline $\mathbf{j}$ & $\begin{array}{l}2013 / 2014 \text { SSTS - } \\
\text { GISS-E2-H } \\
\text { anthropogenic pattern }\end{array}$ & 15,484 & Pre-industrial & $\begin{array}{l}\text { Maximum extent } \\
\text { Northern Hemisphere: 1986/1987 } \\
\text { Southern Hemisphere: } 2007 / 2008\end{array}$ \\
\hline k & $\begin{array}{l}2013 / 2014 \text { SSTS - } \\
\text { GISS-E2-R } \\
\text { anthropogenic pattern }\end{array}$ & 7,220 & Pre-industrial & $\begin{array}{l}\text { Maximum extent } \\
\text { Northern Hemisphere: 1986/1987 } \\
\text { Southern Hemisphere: } 2007 / 2008\end{array}$ \\
\hline I & $\begin{array}{l}2013 / 2014 \text { SSTS - } \\
\text { HadGEM2-ES } \\
\text { anthropogenic pattern }\end{array}$ & 11,034 & Pre-industrial & $\begin{array}{l}\text { Maximum extent } \\
\text { Northern Hemisphere: 1986/1987 } \\
\text { Southern Hemisphere: } 2007 / 2008\end{array}$ \\
\hline m & $\begin{array}{l}2013 / 2014 \text { SSTs - } \\
\text { IPSL-CM5A-LR } \\
\text { anthropogenic pattern }\end{array}$ & 7,730 & Pre-industrial & $\begin{array}{l}\text { Maximum extent } \\
\text { Northern Hemisphere: 1986/1987 } \\
\text { Southern Hemisphere: } 2007 / 2008\end{array}$ \\
\hline $\mathbf{n}$ & $\begin{array}{l}2013 / 2014 \text { SSTs - } \\
\text { IPSL-CM5A-MR } \\
\text { anthropogenic pattern }\end{array}$ & 10,250 & Pre-industrial & $\begin{array}{l}\text { Maximum extent } \\
\text { Northern Hemisphere: 1986/1987 } \\
\text { Southern Hemisphere: 2007/2008 }\end{array}$ \\
\hline $\mathbf{0}$ & $\begin{array}{l}2013 / 2014 \text { SSTS - } \\
\text { MIROC-ESM } \\
\text { anthropogenic pattern }\end{array}$ & 13,322 & Pre-industrial & $\begin{array}{l}\text { Maximum extent } \\
\text { Northern Hemisphere: 1986/1987 } \\
\text { Southern Hemisphere: } 2007 / 2008\end{array}$ \\
\hline
\end{tabular}

We define our best estimate of the percent change in risk 1-in-100-year events $(R R)$ due to human influence as follow:

$R R=(A C E / N E-1) * 100$

where ACE is the fraction of the Actual Conditions simulations exceeding its 1 -in100-year event, and $N E$ is the fraction of the Natural runs exceeding that threshold. We calculate $R R$ for each individual Natural (providing an uncertainty range) and for the pooled Natural, which consists of all ensemble members available pooled 
together, i.e., our best estimate. The effect of having different ensemble sizes on our best estimate of the change in risk in 1-in-100-year precipitation index, pressure index, 30-day peak river flow and 1-day peak river flow is tested by using two methods. First, we calculate the change in risk using only the first 7,220 ensemble members for each Natural experiment (smallest ensemble size available, see Supplementary Table 2). The second method is to increase the ensemble size for each individual Natural to 15,726 (largest ensemble size available, see Supplementary Table 2) by randomly resampling with replacement the available ensemble members. This is repeated 100 times and we present the average, $5^{\text {th }}$ and $95^{\text {th }}$ percentiles obtained in Supplementary Table 3, along with the best estimates shown in the main article and from the first method. The resulting best estimates are consistent for the three methods and show no sign of any systematic effect of having different ensemble sizes.

Supplementary Table 3: Best estimates of the change in risk between Actual Conditions and Natural simulations for three different pooling methods and different variables, along with the $5^{\text {th }}-95^{\text {th }}$ uncertainty range for the third method.

\begin{tabular}{|c|c|c|c|c|c|}
\hline & \multirow{2}{*}{$\begin{array}{c}\text { All members } \\
\text { of each } \\
\text { Natural } \\
\text { ensemble }\end{array}$} & \multirow{2}{*}{$\begin{array}{c}\text { First } 7,220 \\
\text { members of } \\
\text { each Natural } \\
\text { ensemble }\end{array}$} & \multicolumn{3}{|c|}{$\begin{array}{c}\text { Increasing size of each Natural } \\
\text { ensemble to } 15,726 \text { (100 resamples) }\end{array}$} \\
\hline & & & Mean & $5^{\text {th }}$ percentile & $95^{\text {th }}$ percentile \\
\hline Precipitation index & $43 \%$ & $46 \%$ & $45 \%$ & $39 \%$ & $52 \%$ \\
\hline Pressure index & $55 \%$ & $46 \%$ & $50 \%$ & $42 \%$ & $57 \%$ \\
\hline 30-day peak flows & $21 \%$ & $21 \%$ & $22 \%$ & $17 \%$ & $28 \%$ \\
\hline 1-day peak flows & $4 \%$ & $6 \%$ & $5 \%$ & $1 \%$ & $9 \%$ \\
\hline
\end{tabular}

Ref 4 evaluates the RCM's temperature and precipitation over Europe. As Fig. 2 shows the Westerly wind at $200 \mathrm{hPa}$, Supplementary Fig. 6 shows the 1986-2011 January climatology estimated from observations ${ }^{9}$ and in the GCM, along with the bias of the model. Overall the GCM has a good representation of this quantity over the region of interest, although the maximum off the East coast of North America is too weak, and the jet extends too far into Northern Europe. 

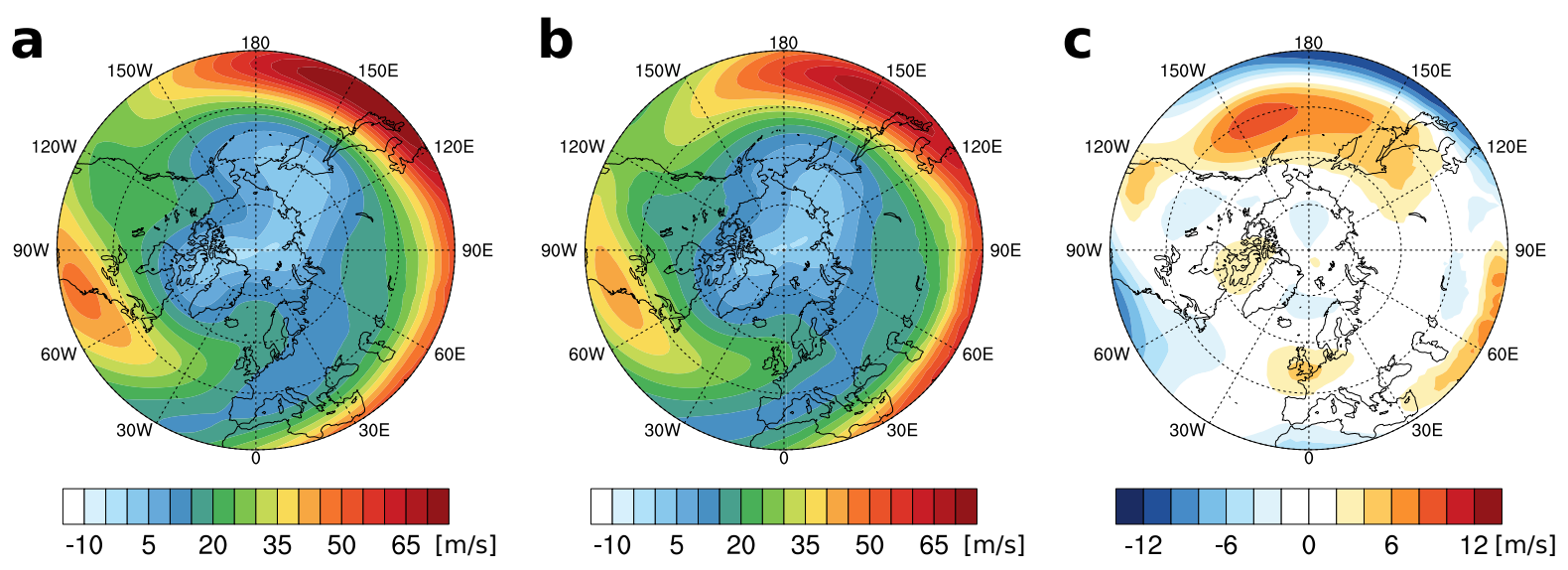

Supplementary Figure 6: The 1986-2011 January Westerly wind climatology in a ERA-Interim ${ }^{9}$ and b HadAM3P. c shows the bias of HadAM3P for the same period.

\section{Regime analysis}

Our different regimes are data-based, and computed for winter (DJF) from the SLP fields of the NCEP reanalysis, which covers years 1948-2014 ${ }^{1}$. We compute the first 10 principal components ${ }^{10}$ (PCs) of the seasonal daily anomalies of SLP over the North Atlantic region $\left(80^{\circ} \mathrm{W}-30^{\circ} \mathrm{E} ; 30^{\circ} \mathrm{N}-70^{\circ} \mathrm{N}\right)$. We then apply a $k$-means clustering classification algorithm ${ }^{11}$ to these principal components, to obtain four weather patterns. These can be characterised as a Blocking (BLO), a North Atlantic Ridge $(A R)$, a Zonal regime (ZO, note that the anomaly centre is south of the NAM/NAO negative centre) and negative North Atlantic Oscillation (NAO-) (Supplementary Fig. 7a-d). We find that the time spent in the zonal regime, ZO, exceeds $83 \%$ for January 2014 , and $70 \%$ in DJF 2013/14, which are both records since 1948. Repeating the cluster analysis with an alternative reanalysis, 20CR, covering 1871-2012 reveals similar frequencies for all four regimes. The frequency of regime $\mathrm{ZO}$ for January 2014 has been previously reached only once since 1871, whereas the mean frequency over DJF 2013/14 has never occurred before in that reanalysis.

We interpolate the SLP of the RCM simulations onto the NCEP grid, to facilitate the comparison of model projections with known weather regimes. The mean winter SLP from the Actual Conditions simulations is subtracted from all RCM simulations. The resulting SLP anomalies are then classified into the four NCEP weather regimes by minimizing a root-mean-square distance, and ensemble model simulations of times spent in each were calculated (Supplementary Fig. 7e-l). 

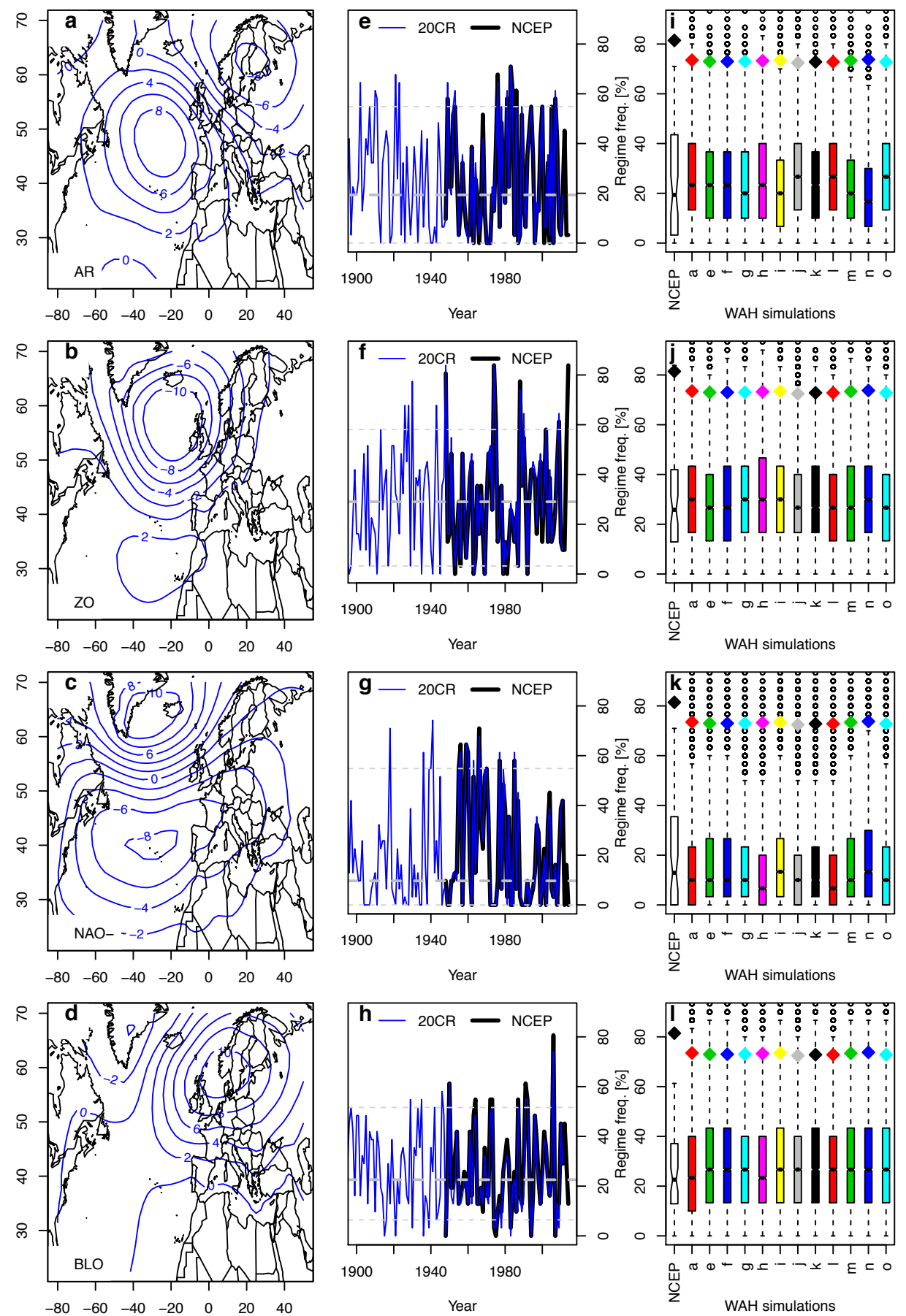

Supplementary Figure 7: Panels (a-d): SLP patterns of the four weather regimes obtained from the January daily averages in the NCEP reanalysis. From top to bottom these are North Atlantic Ridge (AR), Zonal regime (ZO), negative North Atlantic Oscillation (NAO-) and Blocking (BLO). Panels (e-h) show time series of the corresponding weather regime frequency in two reanalysis datasets (NCEP: black line and 20CR: blue line) for January, during the $20^{\text {th }}$ century, with the medians as horizontal dashed lines. (i-I) show the distribution of frequency in each regime from the NCEP reanalysis and the different RCM ensembles; the box and whisker plots show the $25^{\text {th }}$, median and $75^{\text {th }}$ percentiles of the regime frequencies (coloured boxes). The upper whisker is the value of $\min \left(1.5\left(q_{75}-q_{25}\right)+q_{50}\right.$, maxF). The lower whisker comes from a symmetrical formulation. The dots above the upper whisker represent outliers. The diamonds indicate the mean ZO frequency when it exceeds 20 days for comparison with Fig. 4. 


\section{Details of statistical techniques}

Both the Kolmogorov-Smirnov test and the Cramer-von Mises test, used in Fig. 4, are based on the assumption that both samples are drawn from single distributions of continuous variables. While pressure and precipitation are continuous, a potentially important caveat is that we are varying the forcing of the natural ensemble discontinuously, by selecting one of 11 SST patterns from the CMIP5 ensemble. Nevertheless, the size of the noise due to internal variability and the mean response across the CMIP5 models both significantly exceed the discrete sampling intervals, so we do not consider this to be a serious issue and it clearly does not impact our non-parametric uncertainty estimates on the one-dimensional return period plots.

Fig. 5 and Supplementary Figs 5 show return periods. The horizontal axis is actually the rank of each ensemble member but labelled as the equivalent return period. The longer the return period, the smaller the sample size and the greater the uncertainty, so spread can be seen to generally increase with return period.

In Fig. 5c, observed Southern England monthly winter precipitation amounts show no statistically significant change in extreme values between the recent period and a century ago. This is assuming a Generalized Pareto Distribution that scales with lowpass (4-year running mean) filtered global mean temperature but the signal-to-noise ratio for precipitation is so low that a linear trend gives the same answer. The significance was assessed using a non-parametric bootstrap test using all data points. However, this test would not detect any change smaller than a factor of about four due to the short observational record so this does not preclude anthropogenic forcing having a smaller influence on winter precipitation. 


\section{Separation of the dynamical and thermodynamical effects on the changes in extreme precipitation}

Supplementary Fig. 8 shows the difference in precipitation between the wettest $1 \%$ Actual Conditions and wettest $1 \%$ Natural, both selected using the precipitation index. We wish to estimate the separate contributions to the increase in precipitation in the Actual Conditions simulations compared to the pooled Natural simulations for the 1-in-100-year event potentially given by thermodynamic processes (i.e. the Clausius-Clapeyron relationship ${ }^{12}$ ) and by dynamic ones (via changes of circulation caused by anthropogenic forcing).

The idea of our method is to adjust each of the pooled Natural simulations to remove the effects of any circulation changes, which we assume to be represented by the pressure index. Specifically, we adjust the ranks in the "return period" plots so as to force the distribution of the pressure index to match the Actual Conditions simulations.

As a first step, we calculate histograms of the pressure index at $1 \mathrm{hPa}$ resolution for Actual Conditions and Natural. The ratio between their frequencies for each bin is used as a weight for the corresponding values of the pooled Natural ensemble. We then plot the pressure or precipitation index of each Natural ensemble member, not against the original rank, but against an adjusted rank, calculated by dividing the sum of all weights by the cumulative sum up to the given sorted pressure or precipitation index. Fig. 4c shows the original and adjusted Natural pressure indices along with the Actual Conditions pressure indices, showing how closely the adjustment fits. Fig. 4d then shows the corresponding plot for the precipitation index. The increase in risk for the 1-in-100-year event in Actual Conditions due to anthropogenic forcing decreases from $43 \%$ to $28 \%$ when the dynamic effect is removed, implying that both potential effects do play a role, with around a $1 / 3$ of the change in risk due to changes in circulation, and $2 / 3$ due to the Clausius-Clapeyron relationship. 


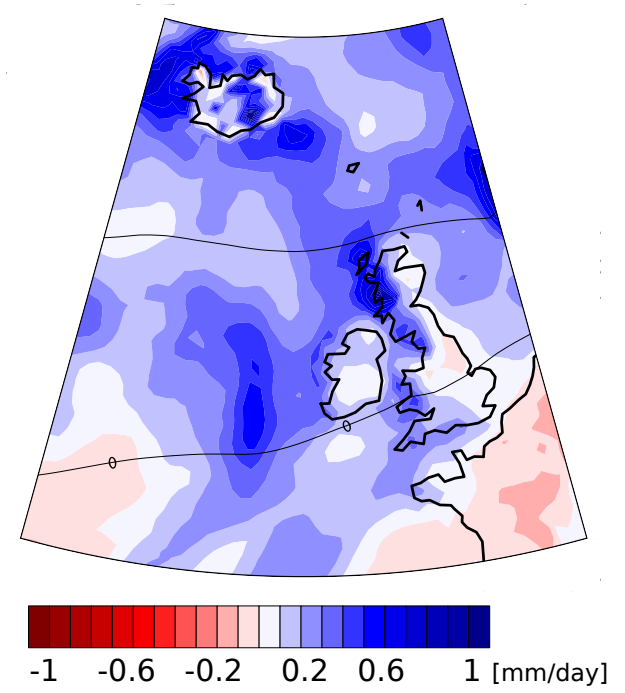

Supplementary Figure 8: Difference of modelled January mean precipitation (colours) and sea level pressure (contours: $\mathrm{hPa}$ ) between the wettest $1 \%$ Actual Conditions simulations and the wettest $1 \%$ Natural simulations.

\section{Hydrological modelling}

\subsection{The rainfall-runoff model}

River flows are simulated for the Thames at Kingston using the Climate and Landuse Scenario Simulation In Catchments model, CLASSIC ${ }^{13}$, including its temperature-based snow module ${ }^{14}$. CLASSIC was specifically developed for simulating the impacts of climate and land-use change in large catchments in Britain, including the Thames, and so is the ideal choice for this study. It has been used for a number of studies of the potential impacts of climate change on floods in catchments across Great Britain ${ }^{15,16}$ as well as a previous flood event attribution study ${ }^{17}$; the catchment of the Thames to Kingston was included in each case.

CLASSIC is a semi-distributed rainfall-runoff model ${ }^{13}$ applied on a grid (here set as $10 \times 10 \mathrm{~km}$ ) with the catchment boundary overlaid (Supplementary Fig. 9), and simulates daily mean river flows using input time-series of daily precipitation and monthly potential evaporation (PE) for each grid box. Parameter values in the model are determined using generalized relationships with physical catchment properties based on land use, soil type and topography ${ }^{13}$. The snow module is used as a preprocessor on the precipitation and operates with accounting in separate elevation zones, areas of which are derived for each grid box using data from the Integrated Hydrological Digital Terrain Model IHDTM ${ }^{18}$. Inclusion of the snow module requires 
daily mean temperature data, and its corresponding altitude in order to lapse the data to the elevation zones within each grid box.
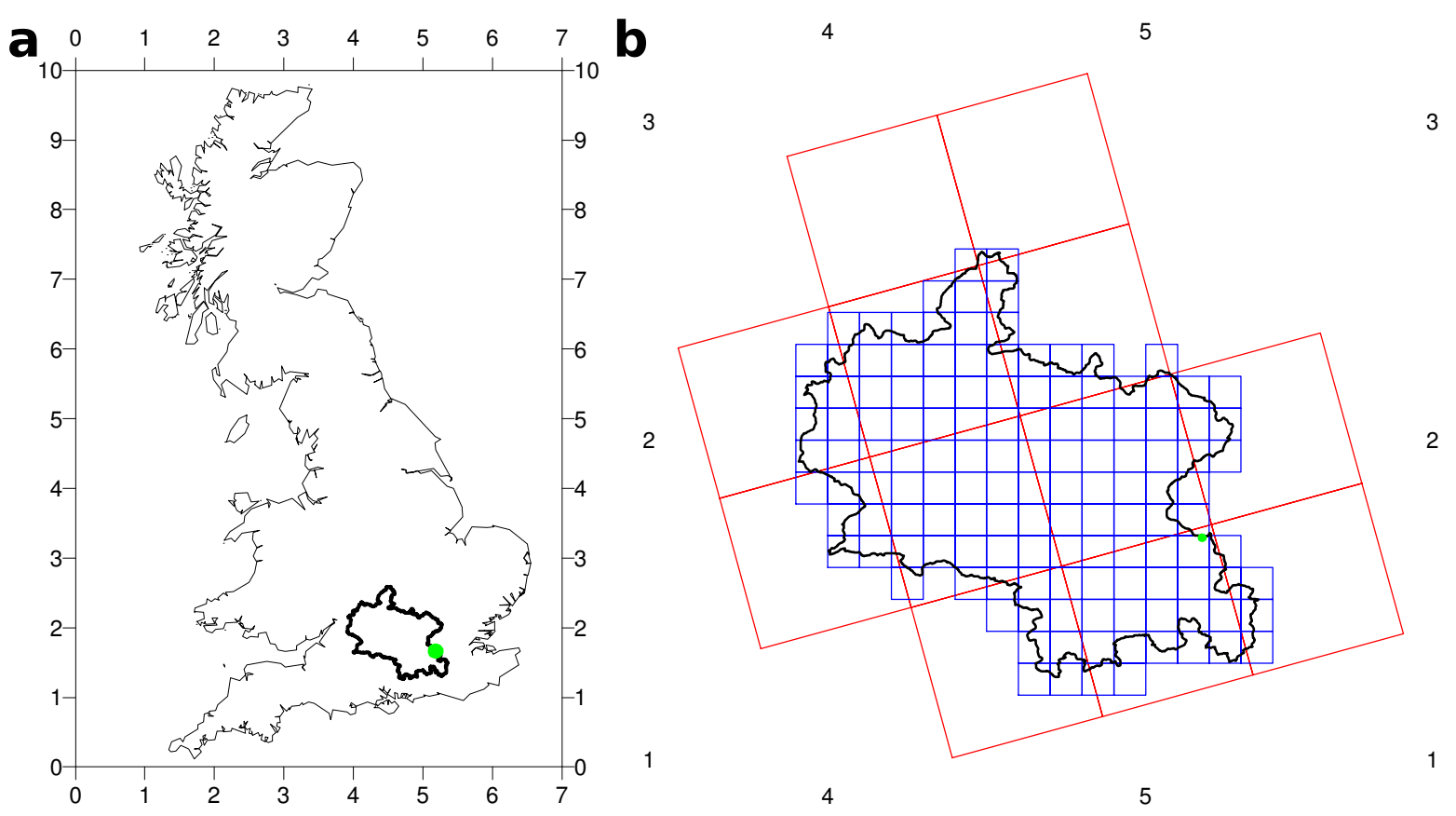

Supplementary Figure 9: a The outlet location (green dot) and catchment boundary (black) for the Thames at Kingston. b shows the $10 \times 10 \mathrm{~km}$ CLASSIC grid (blue) and the $\sim 50 \times 50 \mathrm{~km}$ climate model grid (red) over the catchment. The axes are labelled with the GB national grid.

\subsection{The Thames catchment}

The Thames is one of the largest rivers in Great Britain, and Kingston, west London, is the location of its lowest gauging station (Supplementary Fig. 9), which lies at the tidal limit and has been recording since 1883; both observed (gauged) flows and naturalised flows (gauged flows adjusted to allow for the net impact of upstream abstractions and discharges ${ }^{19}$ ) are available from the UK National River Flow Archive (nrfa.ceh.ac.uk). The catchment is very heterogeneous, particularly in terms of hydrogeology with significant areas of both responsive clay soils and much more slowly responding soils underlain by chalk or limestone aquifers ${ }^{20}$. The latter give the catchment a relatively high baseflow index of 0.64 (the proportion of flows derived from groundwater sources), and mean that antecedent conditions, and therefore temporal patterns of precipitation and temperature over multi-day to seasonal durations, are an important influence on river flows in the catchment. 
Supplementary Fig. 10 shows observed and naturalised flows for the Thames at Kingston for April 2013-March 2014, along with mean, maxima and minima through the year using naturalised flows since 1961 and since 1883, for several durations. These show that the flows in DJF 2013/2014 were more unusual in terms of longer durations than daily means ${ }^{21}$. The 60-day mean flow beginning late December 2013, combining the two main periods of rainfall in January and February 2014, is the highest in the 130-year record by around 30\% whereas the peak daily flow in February 2014 was exceeded in six previous years. Following the wet summer of 2012, mean daily flows were slightly higher than average in April 2013 (green line compared with dashed blue line) but, with a drier summer in 2013, by September flows were below average and in mid-December were well below average for the time of year. Hence, antecedent conditions would have mitigated the impact of the rainfall in the latter part of December 2013 and high groundwater levels would not have been a contributory factor until February 2014.

Also shown in Supplementary Fig. 10 are flows simulated with CLASSIC using observed input data (CEH-GEAR $1 \mathrm{~km}$ daily precipitation ${ }^{22}$, MORECS $40 \mathrm{~km}$ monthly $\mathrm{PE}^{23}$ and $5 \mathrm{~km}$ Met Office temperature ${ }^{24}$, each transformed onto the model $10 \mathrm{~km} \times 10 \mathrm{~km}$ grid). These show that CLASSIC performs well for this period over all durations, with the rapid increase in flows in mid-December well-replicated (note that although flows are only shown for one year, the simulation was run from January 2010 to allow for the influence of antecedent conditions). A recent study used CLASSIC to simulate daily flows for the Thames at Kingston for $1890-2013^{25}$ and showed relatively good performance throughout the period, despite changes in rainfall seasonality for example, demonstrating the relative stability of the catchment's response to climatic inputs and thus the stability of the model parameter values. 
a
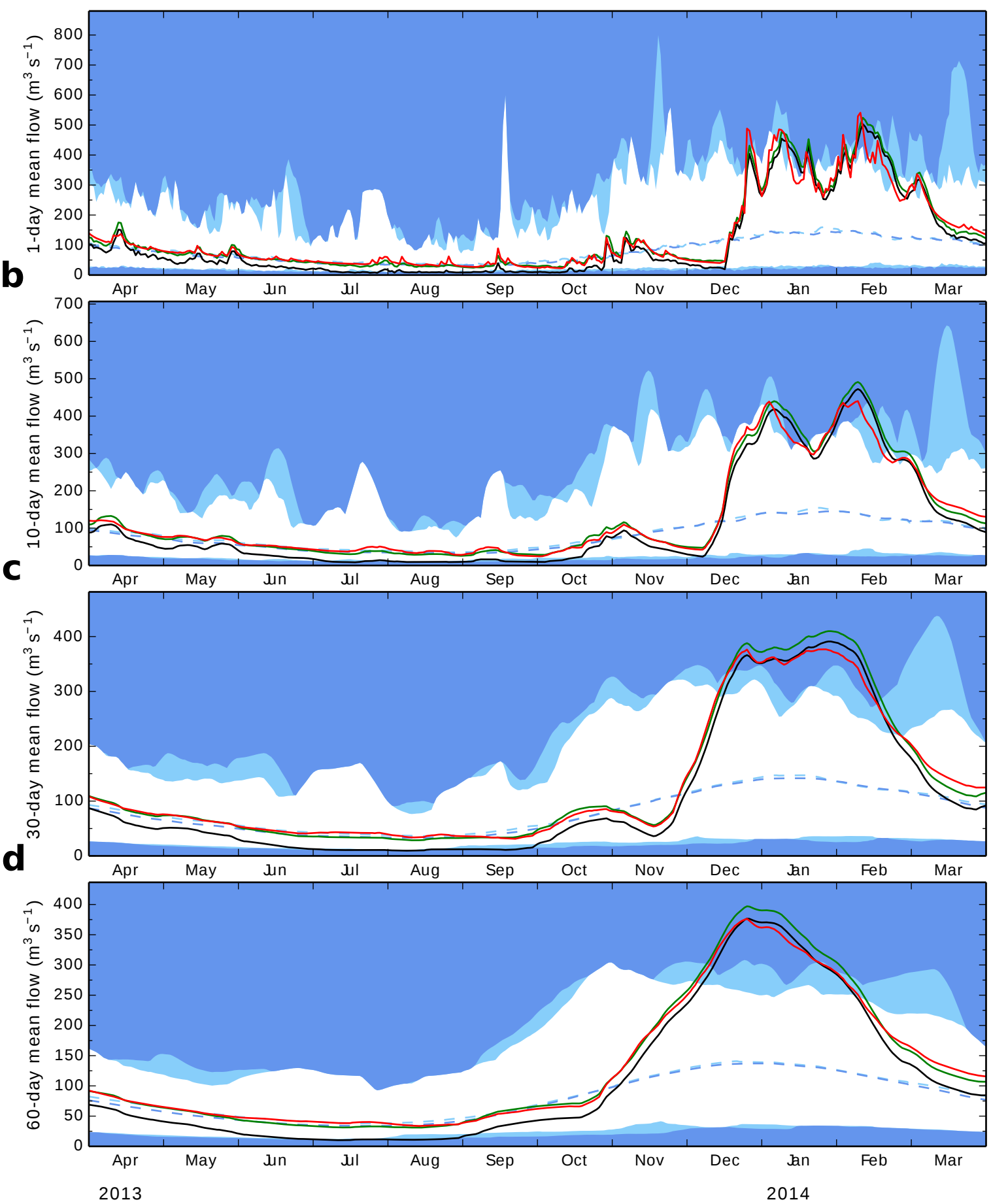

Supplementary Figure 10: Hydrographs showing observed (black), naturalised (green) and simulated (using CLASSIC: red) flows for the Thames at Kingston for April 2013 to March 2014, for four durations (1-, 10-, 30- and 60-day mean flows in a-d). Shaded areas indicate maxima and minima from naturalised flows up to March 2013, from 1961 (pale blue) and 1883 (dark blue), with the respective mean naturalised flows shown as blue dashed lines. The dates are for the start of the averaging-period. 


\subsection{Use of ensemble data to drive CLASSIC}

The precipitation and temperature data required by CLASSIC are available directly from the climate model runs, but PE data are not and so have been estimated from the temperature data using the Oudin formula ${ }^{26}$. This method of calculating PE has been shown to perform well when using baseline climate model data ${ }^{27,28}$ (although projections for future PE using temperature-based formulae can differ from projections using more physically-based formulae, and there is on-going debate about the best formulae to use ${ }^{29}$ ). Precipitation and PE are then converted from the climate model grid to the CLASSIC grid using area-weighting, plus extra weighting for precipitation based on standard average annual rainfall patterns ${ }^{30}$. The climate model temperature data are lapsed to the CLASSIC grid, using altitudes from the orography file of the climate model and from the IHDTM.

For each ensemble member, CLASSIC was then run for the period January 2010February 2014, using observed data up to $10^{\text {th }}$ December 2013 followed by the simulated data from $11^{\text {th }}$ December 2013 up to the end of February 2014. This allows plenty of time for spin-up of stores, given the importance of antecedent conditions on flows in DJF 2013/2014. The first 10 days of the RCM simulations are not used so as to allow the atmosphere to spin up. Precipitation in the first few days of the Natural simulations is unrealistically high, but has stabilised after 10 days (due to these simulations being started on the $1^{\text {st }}$ December 2013 from restart files from the $30^{\text {th }}$ November 2013 using a slightly different set of delta SSTs). CLASSIC was run both with and without the snow module, to assess the importance of snow processes on the results.

\subsection{Analysis of flow data}

From each run of CLASSIC, the daily mean flows for DJF 2013/2014 are extracted. These are shown in Supplementary Fig. 11 as envelopes around the observed flows over the period, with $10^{\text {th }}, 25^{\text {th }}, 50^{\text {th }}, 75^{\text {th }}$ and $90^{\text {th }}$ percentiles shown for each ensemble separately (Actual Conditions, a, and Natural, e to o) and for the 11 Natural ensembles pooled together (e-o). Supplementary Fig. 11 shows how extreme the observed flows in this period were, relative to the ensemble simulated flows, but the ensemble minima and maxima contain the observed flows. The maxima from the pooled Natural ensemble are generally higher than those from the 
Actual Conditions ensemble, due to the much larger size of the former, but there is little difference for the other percentiles. Note that the percentiles from the ensemble simulations would not be expected to follow the peaks/troughs of the observed flows - the climate model cannot reproduce the actual, effectively random pattern of chaotic "weather noise".

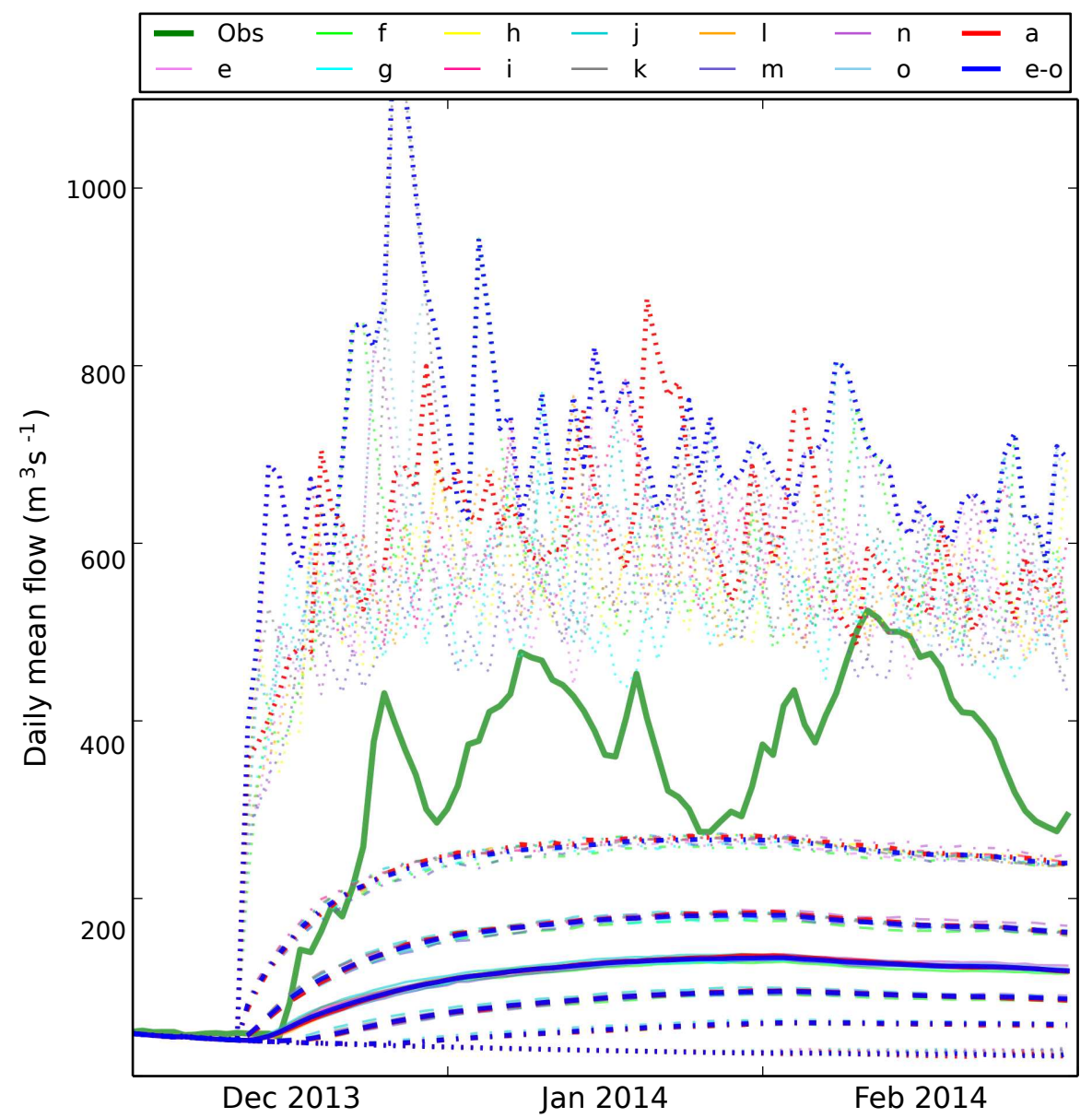

Supplementary Figure 11: Simulated daily mean flow time-series (modelled with the snow module), plotted as probabilistic envelopes for each ensemble and each day, compared to the observed (naturalised) daily mean flows (green solid line). For each ensemble (Actual - a and Natural - e to o) and for the pooled Natural ensemble (e-o), the $50^{\text {th }}$ (solid), $25^{\text {th }}$ and $75^{\text {th }}$ (dashed) and $5^{\text {h }}$ and $95^{\text {th }}$ (dot-dashed) percentiles are shown, along with minima and maxima (dotted).

To analyse flow peaks at a range of durations, the daily mean flows are first turned into running mean flows for longer durations (10-, 30- and 60-days), then the maximum flow is extracted at each duration, for each run. These calculated maxima are grouped by ensemble, and plotted against return period using the Gringorten plotting position, an approximate unbiased estimator of exceedance probability, the reciprocal of the return period ${ }^{31}$. The 11 Natural ensembles are also pooled and 
plotted as one large ensemble. The Actual Conditions and pooled Natural ensembles are also resampled 10,000 times (to assess sampling uncertainty), to calculate $5^{\text {th }}$ $95^{\text {th }}$ percentile confidence ranges. The results when run with the snow module are shown in Supplementary Fig. 12 (left), while the equivalent results when run without the snow module are shown in Supplementary Fig. 13 (left).
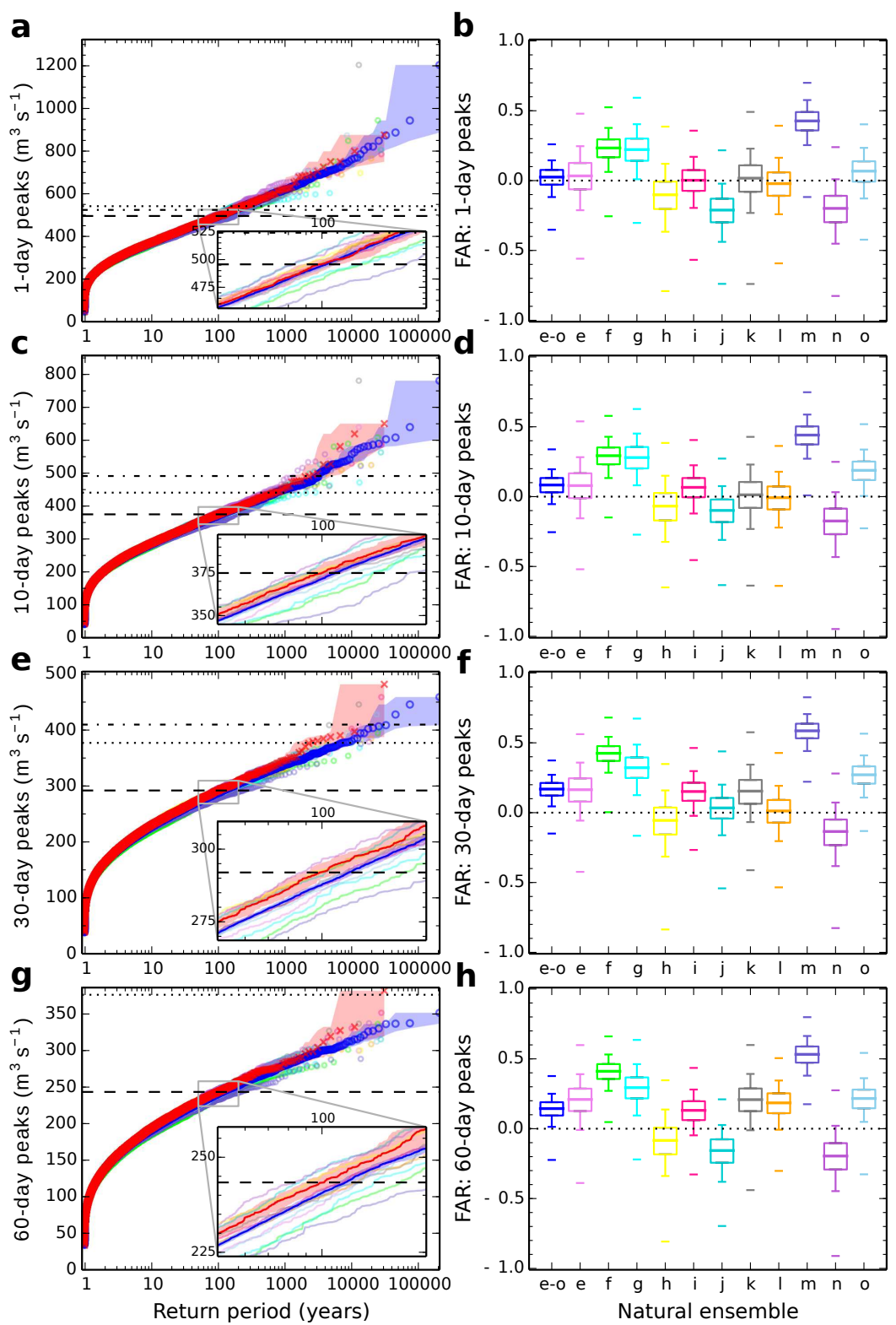

Supplementary Figure 12: Plots of simulated flood peaks (modelled with the snow module) against return period (left) and box-plots of FAR ranges (right) for durations of 1-, 10-, 30- and 60-day (top to bottom). The flood peak plots show the Actual Conditions ensemble (red crosses), the pooled Natural ensemble (large blue circles) and each of the Natural ensembles individually (smaller circles) (note that the inset plots show coloured lines, rather than symbols, for clarity). Also shown for each duration are horizontal lines giving the peaks from observed flows (dot-dashed) and from flows simulated with observed inputs (dotted), and the simulated 100-year return period flow from the Actual Conditions ensemble (dashed), used as the threshold for calculating FAR. The box- 
plots show the FAR, with uncertainty ranges, calculated for the pooled Natural ensemble ("e-o") and each of the Natural ensembles ("e"-"o") individually. The boxes show the $25^{\text {th }}-50^{\text {th }}-75^{\text {th }}$ percentile range, while the whiskers show the $5^{\text {th }}-95^{\text {th }}$ percentile range. Markers outside the whiskers show the overall extrema.
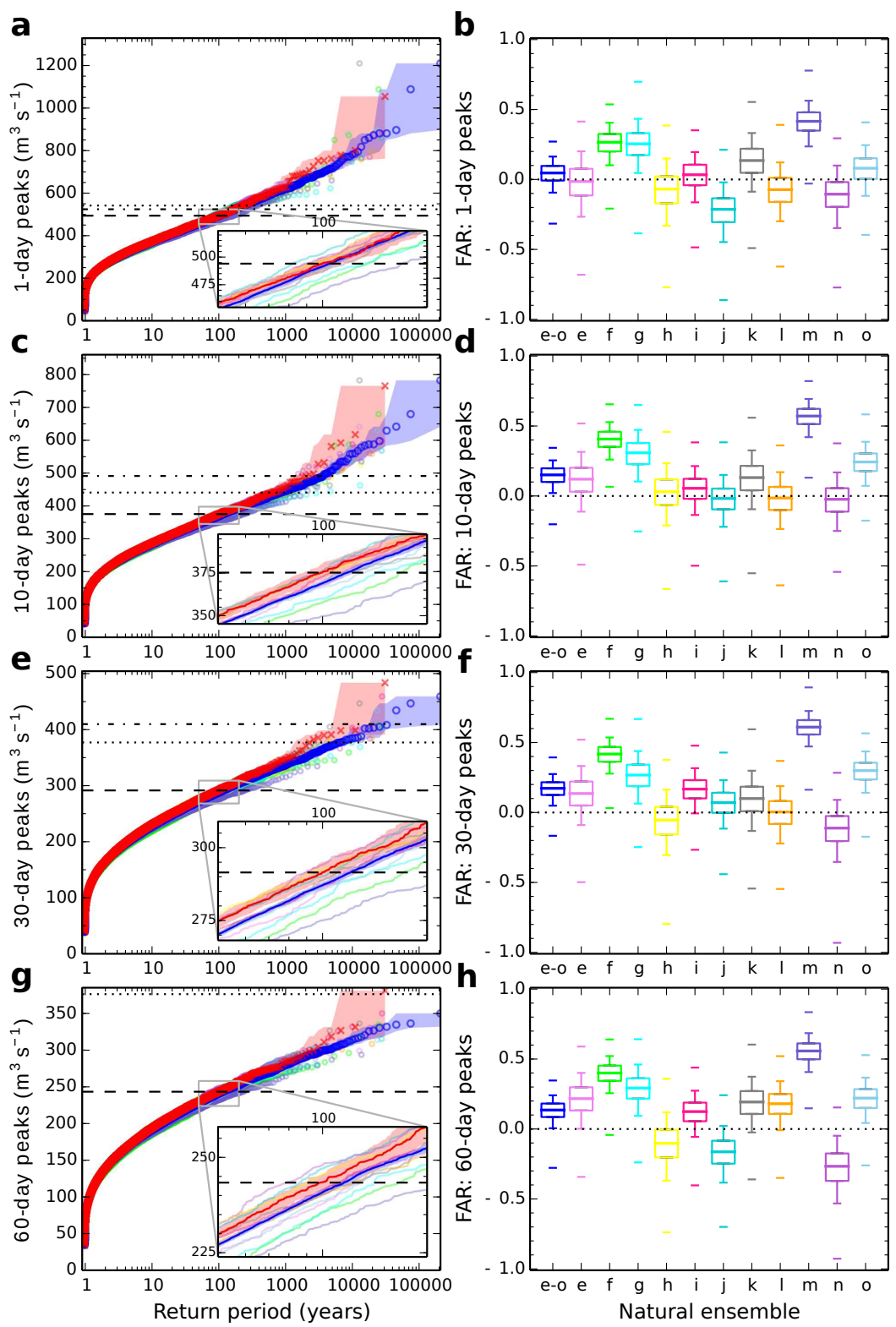

Supplementary Figure 13: As Supplementary Fig. 12 but modelled without the snow module.

The Fraction of Attributable Risk (FAR) is given by:

$F A R=1-(N E / A C E)$

where $A C E$ is the fraction of the Actual Conditions runs with peak flows exceeding a given threshold, and $N E$ is the fraction of the Natural runs exceeding the threshold ${ }^{32}$. This is calculated for the pooled Natural ensemble and for each individual Natural ensemble separately, relative to the threshold given by the Actual Conditions 1-in- 
100-year flow, and uncertainty ranges are calculated by resampling (Supplementary Figs 12 and 13 right). Positive FAR indicates that past emissions have increased the chance of extreme river flows, and hence flooding, whereas negative FAR indicates a decrease. The magnitude of FAR for the pooled Natural ensemble varies with duration; there is a large positive influence on 30 -day and 60 -day peak flows (>95\% confidence), but a lesser positive influence on 10-day peak flows ( $>75 \%$ confidence) and only a small positive influence on daily peak flows ( $>60 \%$ confidence) with the snow module (Supplementary Fig. 12). Four of the individual Natural ensembles show a decreased chance for the best estimate for some or all durations. Without the snow module (Supplementary Fig. 13) the positive influence on both 10-day and daily peak flows increases (although the confidence for the increase in daily peak flows is still only just over $70 \%$ ). Thus changes in snow moderate the increases that would otherwise have occurred in shorter duration peak flows, consistent with results for the floods of Autumn/Winter $2000^{17}$. This result is also consistent with analyses showing that, while snow has historically been one of the main flood-generating mechanisms on the lower Thames (typically via rapid melt of large accumulations coincident with the occurrence of heavy rainfall), its relative contribution has declined over time ${ }^{19,25}$.

The other main flood-generating mechanism on the lower Thames is sustained heavy rainfall (typically over 4-7 days) on saturated ground ${ }^{19}$. To investigate the influence of extreme rainfall accumulations on the flow results, similar analyses are done for maximum rainfall accumulations over a range of durations as are presented above for peak flows. That is, using the climate model rainfall data for a grid box over the Thames, the maximum accumulation over 1, 5, 10 and 30 days is calculated for each run $\left(11^{\text {th }}\right.$ December 2013 to end of February 2014). For each duration, the rainfall accumulations are plotted against return period (Supplementary Fig. 14 left) and FAR values are calculated relative to the threshold given by the Actual Conditions 1-in-100-year accumulation, with uncertainty ranges calculated by resampling (Supplementary Fig. 14 right). These plots show that, while there is a large positive influence of past emissions on extreme 30-day rainfall accumulations, there is a smaller influence on shorter duration accumulations, especially the 5 day accumulation, thus explaining the lower influence on daily peak flows than 30-day peak flows for the Thames at Kingston. 

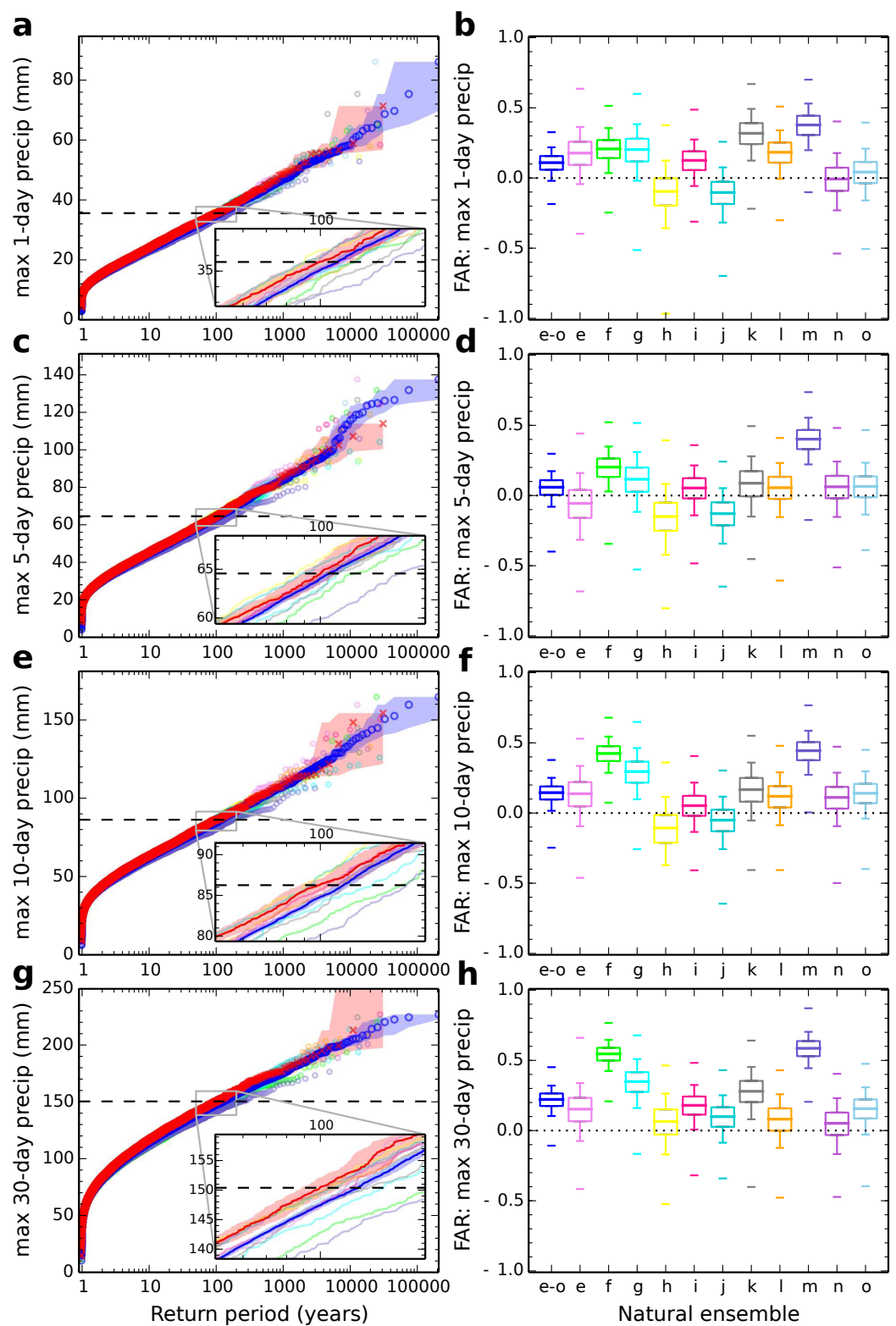

Supplementary Figure 14: Plots of maximum rainfall accumulations against return period (left) and box-plots of FAR ranges (right) for durations of 1, 5, 10 and 30 days (top to bottom). The rainfall accumulation plots show the Actual Conditions ensemble (red crosses), the pooled Natural ensemble (large blue circles) and each of the Natural ensembles individually (smaller circles) (note that the inset plots show coloured lines, rather than symbols, for clarity). Also shown for each duration is a horizontal line showing the 100 -year return period rainfall accumulation from the Actual Conditions ensemble (dashed), used as the threshold for calculating FAR. The boxplots show the FAR, with uncertainty ranges, calculated for the pooled Natural ensemble ("e-o") and each of the Natural ensembles ("e"-"o") individually. The boxes show the $25^{\text {th }}-50^{\text {th }}-75^{\text {th }}$ percentile range, while the whiskers show the $5^{\text {th }}-95^{\text {th }}$ percentile range. Markers outside the whiskers show the overall extrema. 


\section{Flood inundation modelling and indicative flood damages}

This part of the analysis is based on flood maps developed using a combination of hydrological frequency analysis and hydrodynamic flood flow modelling, following a methodology previously applied ${ }^{33}$ for national flood risk mapping in England. Firstly, the methods for statistical analysis of river flooding set out in the industry-standard "Flood Estimation Handbook"34 are applied to watercourses in the Thames catchment upstream of Kingston to derive estimates of flood flows at approximately every 200 metres along the stream network for five annual exceedance probabilities: $1 / 20,1 / 75,1 / 100,1 / 200,1 / 1000$. The analysis includes all watercourses draining areas of more than $3 \mathrm{~km}^{2}$. Then a hydrodynamic model is applied to simulate the limits of possible floodplain inundation (i.e. areas "at risk" of flooding) for each set of flow estimates. The software used, JFlow+, solves the two-dimensional depthaveraged shallow water equations with a finite volume implementation of Roe's scheme $^{35,36}$ and has been demonstrated to be suitable for flood risk modelling in benchmark tests published by the official flood management authority in England ${ }^{37}$. We apply it on a $5 \mathrm{~m}$ horizontal resolution grid with the ground elevations derived primarily from airborne LiDAR survey over the urban areas. The vertical resolution in LiDAR-derived terrain models is variable, but vertical root mean square errors are typically of the order of $\sim 50 \mathrm{~mm}^{38}$.

Floodplain inundation is modelled for a notional world without flood defences, which would mitigate the actual risk in any specific flood event. This approximation, which we return to later, helps to assess the effects of climate forcing in isolation from other anthropogenic factors, and is consistent with the reporting of risk in official flood management plans ${ }^{39}$. The resulting inundation maps are envelopes representing areas that could potentially be flooded with a given annual probability. Ordnance Survey "AddressPoint" data is then used to identify and count the properties within these areas. Supplementary Fig. 15 represents the number of properties thereby assessed to be at risk of flooding, with likelihood greater than the specified annual probability, in the absence of flood defences. By interpreting the annual exceedance probability of modelled river flows at Kingston as an index variable representing the severity of flooding in the catchment, Supplementary Fig. 15 is used as a lookup function to estimate, as a first approximation, how many properties could be at risk for any ensemble member. 


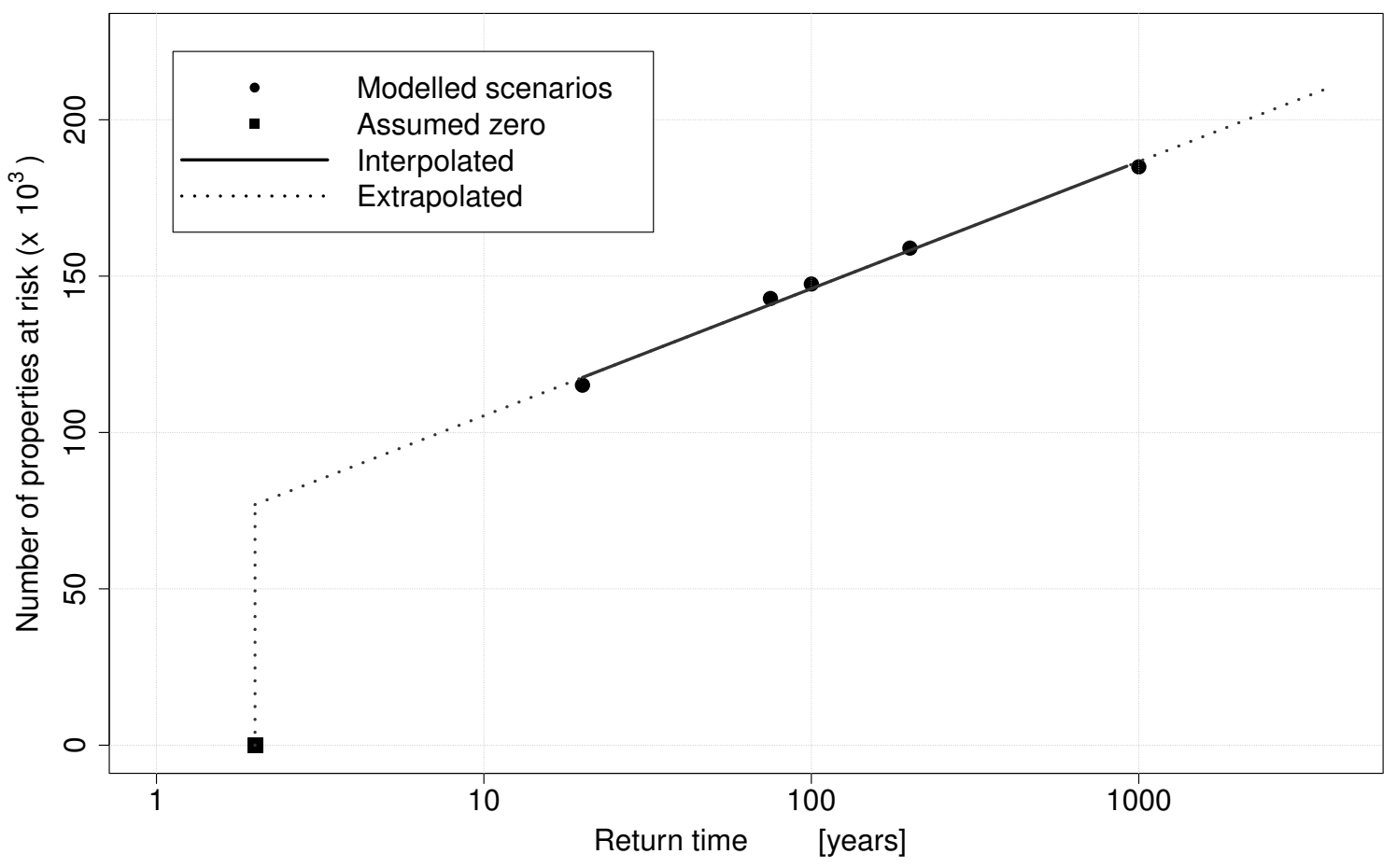

Supplementary Figure 15: Number of properties individually at risk of flooding from the River Thames upstream of Kingston with annual probability greater than $1 / T$, not accounting for flood defences, as a function of return period $T$. Five scenarios were modelled (solid dots) for the specified river flow annual exceedance probabilities on watercourses draining sub-catchments larger than $3 \mathrm{~km}^{2}$.

This relationship is adopted as an approximate impact function, applied so as to obtain an indication of the number of properties flooded in each of over 130,000 ensemble simulations of a complex hydro-meteorological model chain. It is acknowledged that this does not account for uncertainties in the flood inundation modelling process, nor the effect of biases in the outputs of the hydro-meteorological modelling chain relative to actual extreme flows in the Thames catchment. A comprehensive uncertainty analysis of the entire modelling chain would ideally be performed, but was not feasible in the present study. However the property counts for the Actual Conditions simulations are broadly in line with the Environment Agency's Thames Catchment Flood Management Plan ${ }^{34}$, which estimated that approximately 135,000 properties would have more than a 1 -in-100 chance of riverine flooding in any one year, without flood defences. That figure differs in detail from the estimates adopted here because it is based on a composite of several inundation model outputs, and also different property datasets and property counting assumptions. 
To assess the difference in the number of properties at risk of flooding between Actual Conditions and Natural, the frequency distributions of the simulated river flows at Kingston are derived from the hydrological model outputs for the Actual Conditions case, and for each of the Natural ensembles. For each ensemble, the Natural forcing river flows $Q$ expressed on the physical river flow scale, are compared with the distribution of flows from the Actual Conditions simulations, $G_{A}(Q)$, to calculate the corresponding annual probabilities of exceedance $1-G_{A}(Q)$ on the Actual Conditions scale. This effectively translates the empirical distribution of peak flows from the Natural ensembles onto the same scale as the Actual Conditions simulations, allowing the relationship shown in Supplementary Fig.15 to be used to estimate the change in number of properties at risk for return times on the Actual Conditions scale, as shown in Fig. $5 f$.

Flood protection measures within the Thames river basin have evolved as a complex mixture of raised embankments, artificially straightened drainage channels, river diversions and other structures. Official flood management plans ${ }^{40}$ describe how the geology of the Thames floodplain makes construction of raised flood defences impractical in many places, and show that although there are numerous assets acting to reduce flood risk, only $3 \%{ }^{40}$ of the total floodplain area is classified as being protected by "significant" flood defences, benefitting $5 \%$ of properties that would otherwise be at risk of flooding with a $1 \%$ or greater annual probability. Some $10 \%$ of the floodplain is classed as heavily populated and not protected by flood defences, and these areas contain around $40 \%$ of properties at risk (numbering 56,000). Approximately $69 \%$ of the Thames floodplain (or $14 \%$ of properties at risk) is classed as being in "open floodplain", which includes a mixture of defended and undefended areas. Neglecting the role of flood defences is thus considered a reasonable approximation for the purposes of this analysis.

Sensitivity of the estimated change in risk to the assumptions made about flood defences can be assessed in terms of the average annual economic cost of flooding. The annual average flood damage for a typical UK residential property without protection is estimated $^{41}$ to be $£ 4,947$ (at 2015/16 prices), hence the annual economic cost associated with the changes in risk attributable to human-induced climate change in this study can be estimated as between approximately $-£ 19.8$ million (a reduction corresponding to 4000 fewer properties at risk) and $+£ 39.6$ 
million (an increase corresponding to 8,000 more properties at risk). The most favourable standard of protection for areas benefitting from "significant" defences in the Thames catchment is reported to be $1 / 200$ annual probability ${ }^{40}$, for which the average annual damages of a typical property reduce ${ }^{41}$ to $£ 40$. Assuming that flood defences of this standard would have benefitted the same proportion of properties in any of the Natural ensembles as in the actual catchment (i.e. $5 \%$ of properties, see above), then the upper bound of the change in risk attributable to climate change would be reduced by $£ 1.96$ million to $£ 37.6$ million, a relatively insignificant reduction.

The results presented here are intended as a realistic indication of the potential flood risk, under different climatic forcing scenarios, based on detailed contemporary flood mapping and property data. Inputs to CLASSIC are spatially distributed on a grid, as are its internal runoff calculations, but the runoff is then routed to the catchment outlet at Kingston in order to predict the river flow there, which is the primary model output. In the absence of spatially distributed estimates of river flow, the return period $T$ (years) of the daily peak river flows at Kingston is applied as an indicator of the relative extremeness of flooding throughout the catchment. This approximation neglects the spatio-temporal details of individual events, but is consistent with the strong spatial dependence in extreme river flows in this catchment, especially for prolonged flood events in the winter season ${ }^{42}$.

Also the figures are based on a recent snapshot of properties in the Thames region, which is assumed to be a fixed representation of the built environment. The analysis therefore takes no account of how property development might have differed under climate conditions consistent with the Natural forcing.

The results are based on statistical analysis of peak river flows and a robust, physics-based floodplain model applied at a relatively high spatial resolution. However, the modelling necessarily involves some approximation of the real flood risk in the Thames catchment. A further, more comprehensive analysis of potential flood damage for the Thames region might be able to take into account additional factors, including:

- The specific locations, standards and performance of flood defence systems 
- Variation in the spatial extent and timing of flood events

- The evolution and duration of flooding within an event

- The risk associated with sea surge in the tidal Thames (i.e. "downstream" of Kingston)

- Surface water flooding associated with overland runoff and the performance of surface and sub-surface drainage systems

- Groundwater levels

At present the integration of these factors in assessments of flood risk remains a challenge both for researchers and for the flood risk management industry. 


\section{References}

$1 \quad$ Kistler, R. et al. The NCEP-NCAR 50-year reanalysis: Monthly means CD-ROM and documentation. Bull. Amer. Meteorol. Soc. 82, 247-267, doi:10.1175/1520-

0477(2001)082<0247:tnnyrm>2.3.co;2 (2001).

2 Compo, G. P. et al. The Twentieth Century Reanalysis Project. Quarterly Journal of the Royal Meteorological Society 137, 1-28, doi:10.1002/qj.776 (2011).

3 Trenberth, K. E. \& Paolino, D. A. Characteristic Patterns of Variability of Sea Level Pressure in the Northern Hemisphere. Mon. Weather Rev. 109, 1169-1189, doi:10.1175/15200493(1981)109<1169:CPOVOS>2.0.CO;2 (1981).

4 Massey, N. et al. weather@home - development and validation of a very large ensemble modelling system for probabilistic event attribution. Quarterly Journal Of The Royal Meteorological Society In press, doi:10.1002/qj.2455 (2014).

5 Stark, J. D., Donlon, C. J., Martin, M. J. \& McCulloch, M. E. OSTIA : An operational, high resolution, real time, global sea surface temperature analysis system. Oceans 2007 - Europe, Vols 1-3, 331-334 (2007).

6 Donlon, C. J. et al. The Operational Sea Surface Temperature and Sea Ice Analysis (OSTIA) system. Remote Sens. Environ. 116, 140-158 (2012).

7 Schaller, N. et al. The heavy precipitation event of May-June 2013 in the upper Danube and Elbe basins. Bull. Amer. Meteorol. Soc. 95, S69-S72 (2014).

8 Taylor, K. E., Stouffer, R. J. \& Meehl, G. A. An Overview of CMIP5 and the Experiment Design. Bull. Amer. Meteorol. Soc. 93, 485-498 (2012).

9 Dee, D. P. et al. The ERA-Interim reanalysis: configuration and performance of the data assimilation system. Quarterly Journal of the Royal Meteorological Society 137, 553-597, doi:10.1002/qj.828 (2011).

10 von Storch, H. \& Zwiers, F. W. Statistical Analysis in Climate Research. (Cambridge University Press, 2001).

11 Michelangeli, P. A., Vautard, R. \& Legras, B. Weather regimes - Reccurence and quasi stationarity. J. Atmos. Sci. 52, 1237-1256, doi:10.1175/15200469(1995)052<1237:wrraqs>2.0.co;2 (1995).

12 Peixoto, J. P. \& Oort, A. H. Physics of Climate. (American Institute of Physics, 1992).

13 Crooks, S. M. \& Naden, P. S. CLASSIC: a semi-distributed rainfall-runoff modelling system. Hydrol. Earth Syst. Sci. 11, 516-531 (2007).

14 Bell, V. A. \& Moore, R. J. An elevation-dependent snowmelt model for upland Britain. Hydrological Processes 13, 1887-1903, doi:10.1002/(SICl)10991085(199909)13:12/13<1887::AID-HYP846>3.0.CO;2-C (1999).

15 Prudhomme, C., Crooks, S., Kay, A. L. \& Reynard, N. Climate change and river flooding: part 1 classifying the sensitivity of British catchments. Climatic Change 119, 933-948, doi:10.1007/s10584-013-0748-x (2013).

16 Prudhomme, C. et al. Future Flows Hydrology: an ensemble of daily river flow and monthly groundwater levels for use for climate change impact assessment across Great Britain. Earth Syst. Sci. Data 5, 101-107, doi:10.5194/essd-5-101-2013 (2013).

17 Kay, A. L., Crooks, S. M., Pall, P. \& Stone, D. A. Attribution of Autumn/Winter 2000 flood risk in England to anthropogenic climate change: A catchment-based study. Journal of Hydrology 406, 97-112, doi:10.1016/j.jhydrol.2011.06.006 (2011).

18 Morris, D.G. and Flavin, R.W. (1990). A digital terrain model for hydrology. Proceedings of the 4th International Symposium on Spatial Data Handling, Zurich, Volume 1, 250-262.

19 Marsh, T. \& Harvey, C.L. 2012. The Thames flood series: a lack of trend in flood magnitude and a decline in maximum levels. Hydrology Research, 43(3), 203-214

20 Bell, V. A. et al. How might climate change affect river flows across the Thames Basin? An area-wide analysis using the UKCP09 Regional Climate Model ensemble. Journal of Hydrology 442, 89-104, doi:10.1016/j.jhydrol.2012.04.001 (2012).

21 Huntingford, C. et al. Potential influences on the United Kingdom's floods of winter 2013/14. Nature Climate Change 4, 769-777, doi:10.1038/nclimate2314 (2014).

22 Keller, V. D. J. et al. CEH-GEAR: $1 \mathrm{~km}$ resolution daily and monthly areal rainfall estimates for the UK for hydrological use. Earth Syst. Sci. Data 7, 143-155, doi:10.5194/essd-7-143-2015 (2015). 
Hough, M. N. \& Jones, R. J. A. The United Kingdom Meteorological Office rainfall and evaporation calculation system: MORECS version 2.0-an overview. Hydrol. Earth Syst. Sci. 1, 227-239 (1997).

24 Jenkins, G. J., Perry, M. C. \& Prior, M. J. The climate of the United Kingdom and recent trends. (Met Office Hadley Centre, Exeter, UK, 2007).

25 Crooks, S.M. \& Kay, A.L. Simulation of river flow in the Thames over 120 years: Evidence of change in rainfall-runoff response? Journal of Hydrology: Regional Studies, 4, 172-195, doi:10.1016/j.ejrh.2015.05.014 (2015).

26 Oudin, L. et al. Which potential evapotranspiration input for a lumped rainfall-runoff model? Part 2 - Towards a simple and efficient potential evapotranspiration model for rainfall-runoff modelling. Journal of Hydrology 303, 290-306, doi:10.1016/j.jhydrol.2004.08.026 (2005). Kay, A.L. \& Davies, H.N. (2008). Calculating potential evaporation from climate model data: a source of uncertainty for hydrological climate change impacts. Journal of Hydrology 358, $221-$ 239, doi: 10.1016/j.jhydrol.2008.06.005.

28 Prudhomme, C. \& Williamson, J. (2013). Derivation of RCM-driven potential evapotranspiration for hydrological climate change impact analysis in Great Britain: a comparison of methods and associated uncertainty in future projections. Hydrology and Earth System Sciences, 17, 1365-1377, doi:10.5194/hess-17-1365-2013.

29 Kay, A.L., Bell, V.A., Blyth, E.M., Crooks, S.M., Davies, H.N. and Reynard, N.S. A hydrological perspective on evaporation: historical trends and future projections in Britain. Journal of Water and Climate Change, 4(3), 193-208, doi:10.2166/wcc.2013.014 (2013).

Kay, A. L., Reynard, N. S. \& Jones, R. G. RCM rainfall for UK flood frequency estimation. I. Method and validation. Journal of Hydrology 318, 151-162, doi:10.1016/j.jhydrol.2005.06.012 (2006).

Gringorten, I. I. A plotting rule for extreme probability paper. Journal of Geophysical Research 68, 813-814, doi:10.1029/JZ068i003p00813 (1963). Allen, M. Liability for climate change. Nature 421, 891-892 (2003).

33 Bradbrook, K., Waller, S., \& Morris, D. National floodplain mapping: Datasets and methods $160,000 \mathrm{~km}$ in 12 months. Natural Hazards, 36(1-2), 103-123 (2005).

34 Flood Estimation Handbook. (Centre for Ecology and Hydrology, 1999). https://www.gov.uk/government/publications/thames-catchment-flood-management-plan Roe, P.L. and Pike, J. Efficient construction and utilisation of approximate Riemann solutions. In: Glowinski, R. and Lions, J.L. (Eds). Proc. of the Sixth Int. Symposium on Computer Methods in Applied Sciences and Engineering, 499-518, Amsterdam: North-Holland (1984). Toro, E.F. Shock-Capturing Methods for Free-Surface Shallow Flows. Wiley 326 pp. (2001). Benchmarking the latest generation of 2D hydraulic flood modelling packages. Environment Agency Report SC120002, ISBN: 978-1-84911-306-9, Bristol, UK (2013). http://evidence.environmentagency.gov.uk/FCERM/Libraries/FCERM_Project_Documents/SC120002_Benchmarking_2D hydraulic_models_Report.sflb.ashx (Accessed August 2015) Fewtrell, Timothy J., Duncan, Alastair, Sampson, Christopher C., Neal, Jeffrey C., \& Bates, Paul D. (2011). Benchmarking urban flood models of varying complexity and scale using high resolution terrestrial LiDAR data.Physics and Chemistry of the Earth, 36(7), 281-291. doi:10.1016/j.pce.2010.12.011 Thames Catchment Flood Management Plan. Environment Agency ref: LIT 4403, GETH1209BQYL-E-E, Bristol, UK (2009).

40 Thames Catchment Flood Management Plan. Environment Agency ref: LIT 4403, GETH1209BQYL-E-E, Bristol, UK (2009).

41 Penning-Rowsell, E., Priest, S., Parker, D., Morris, J., Tunstall, S., Viavattene, C., Chatterton, J. and Owen, D. Handbook for Economic Appraisal: Flood and Coastal Erosion Risk Management (Flood Hazard Research Centre, 2015).

42 Keef, C., Svensson, C. and Tawn, J. A. Spatial dependence in extreme river flows and precipitation for Great Britain. J. Hydrology 378, 240-252, doi: 10.1016/j.jhydrol. 2009.09.026 (2009). 